Canadian

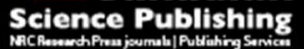

Canadian Journal of Civil Engineering Revue canadienne de génie civil

\title{
RHS-to-RHS Axially Loaded X-Connections near an Open Chord End
}

\begin{tabular}{|r|l|}
\hline Journal: & Canadian Journal of Civil Engineering \\
\hline Manuscript ID & cjce-2017-0148.R1 \\
\hline Manuscript Type: & Article \\
\hline Date Submitted by the Author: & 06 -Jun-2017 \\
\hline $\begin{aligned} \text { Complete List of Authors: } \\
\text { Is the invited manuscript for } \\
\text { consideration in a Special } \\
\text { Issue? : }\end{aligned}$ & $\begin{array}{l}\text { Fan, YuJing; University of Toronto, Civil Engineering } \\
\text { Packer, Jeffrey; University of Toronto, Civil Engineering }\end{array}$ \\
\hline Keyword: & $\begin{array}{l}\text { Nexperimental research < type of paper to review, structure - steel < } \\
\text { Constr.Mate }\end{array}$ \\
\hline
\end{tabular}

SCHOLARONE $^{\text {m }}$

Manuscripts 


\section{Abstract}

(1)

\section{Keywords}

\title{
RHS-to-RHS Axially Loaded X-Connections near an Open Chord End
}

\author{
by \\ YuJing Fan and Jeffrey A. Packer \\ Department of Civil Engineering, University of Toronto, 35 St. George Street, Toronto, ON, M5S 1A4, Canada
}

In all truss-type welded hollow structural section connection design procedures, the chord member is assumed continuous on both sides of the branch. New limits of applicability have recently been advocated, which specify minimum end distances from an open chord end to achieve the full connection strength. To investigate their suitability for rectangular hollow section (RHS) connections, an experimental program consisting of 12 RHS-to-RHS X-connections subject to branch axial compression was undertaken. For connections near a chord end, a modified yield line mechanism controlled. A proposed analytical model is derived, and by evaluating against the experimental results, is shown to accurately predict the yield loads. An EN 1993-1-8 amendment, transcribed from circular hollow section connections, is deemed excessively conservative, and a closed-form solution for the end distance, presented herein, is recommended for use with RHS connections. Alternatively, providing a cap plate is determined to be an effective stiffening method.

9 Steel structures, hollow structural sections, rectangular hollow sections, truss connections, welded joints, chord end effects, static loading, analytical modelling

\footnotetext{
${ }^{*}$ Corresponding author, email: jeffrey.packer@utoronto.ca
} 


\section{Introduction}

Specific research on truss-type, welded hollow structural section (HSS) connections has been conducted since the 1960s, resulting in connection design recommendations published in North America (Packer and Henderson 1997; AISC 2010) and internationally (CEN 2005; Packer et al. 2009; ISO 2013). All of these HSS design recommendations presume that the chord member is continuous for a considerable distance beyond the connection region. There is no established guidance for the case when an HSS branch member is near an open end of an HSS chord member in a girder or truss, which is a problem encountered with trusses supported beneath the bottom chord (such as shown in Fig. 1) or with free chord ends unconnected to another member (such as Warren truss bottom chords where the truss is suspended from connections to the ends of the top chord). In this situation, designers typically resort to strengthening the chord ends, such as capping the chord with an end plate or reinforcing the chord face or walls with stiffening plates. However, there should be a minimum end distance, $e_{\min }$, from an open chord end at which full connection strength can be achieved for an unreinforced connection.

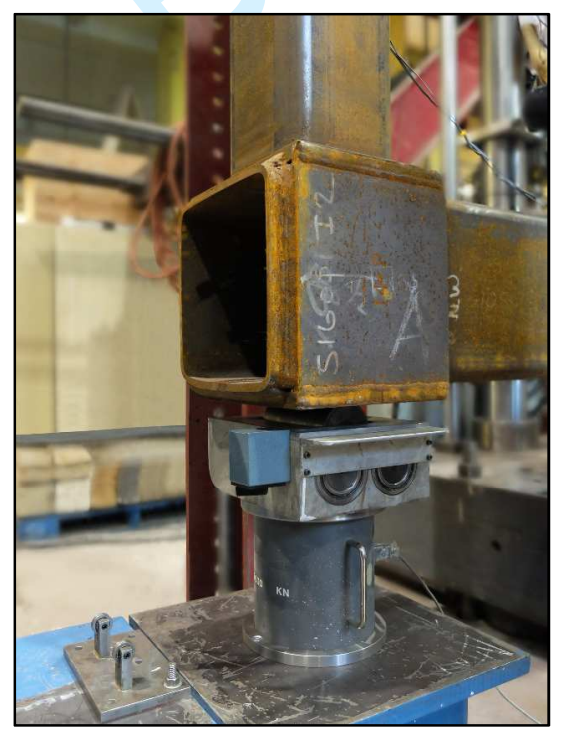

Fig. 1. RHS-to-RHS connection near a truss open end, with chord stiffened

Limited research on HSS chord end effects has been performed for circular hollow section (CHS) welded connections. The numerical investigations on CHS-to-CHS T- and X-connections by van der Vegte and Makino $(2006 ; 2010)$ concluded that chord boundary conditions were not influential if the chord length was greater than 10 times the CHS diameter $\left(10 d_{0}\right)$ for all connection geometries studied. It was shown that the required chord length was primarily a function of the chord wall slenderness $(2 \gamma)$, where less stiffness was provided to limit chord plastification if the connection had thin chord walls compared to thick chord walls. For shorter chord 
lengths, significant differences in the strengths of connections with fixed (capped with end plates) versus free end conditions were determined. Recent numerical studies on transverse branch plate-to-CHS T- and Xconnections by Voth and Packer (2012a; 2012b) also substantiated these results.

The recommendations from this research may be employed for the design of isolated connections in experimental or numerical tests, where the behaviour may be different from that of connections which are part of a framed structure. In addition, they are the basis for the minimum end distance proposed for EN 1993-1-8, in the following amendments to Clause 7.1.2 (9):

"For joints with a chord end not connected to other members, the chord end shall be at a distance of at least $(2 \gamma / 10) d_{0}$ from the heel or toe of the closest brace, with a minimum of $2.5 d_{0}$. For RHS chords, substitute $d_{0}$ by the largest of $b_{0}$ or $h_{0}$. Otherwise, the end shall be welded to a cap plate with a thickness of at least $1.5 t_{0}$, at a minimum distance of $0.5 d_{0}(1-\beta)$ or $0.5 b_{0}(1-\beta)$ from the brace toe or heel of the joint."

This end distance requirement is illustrated in Fig. 2.

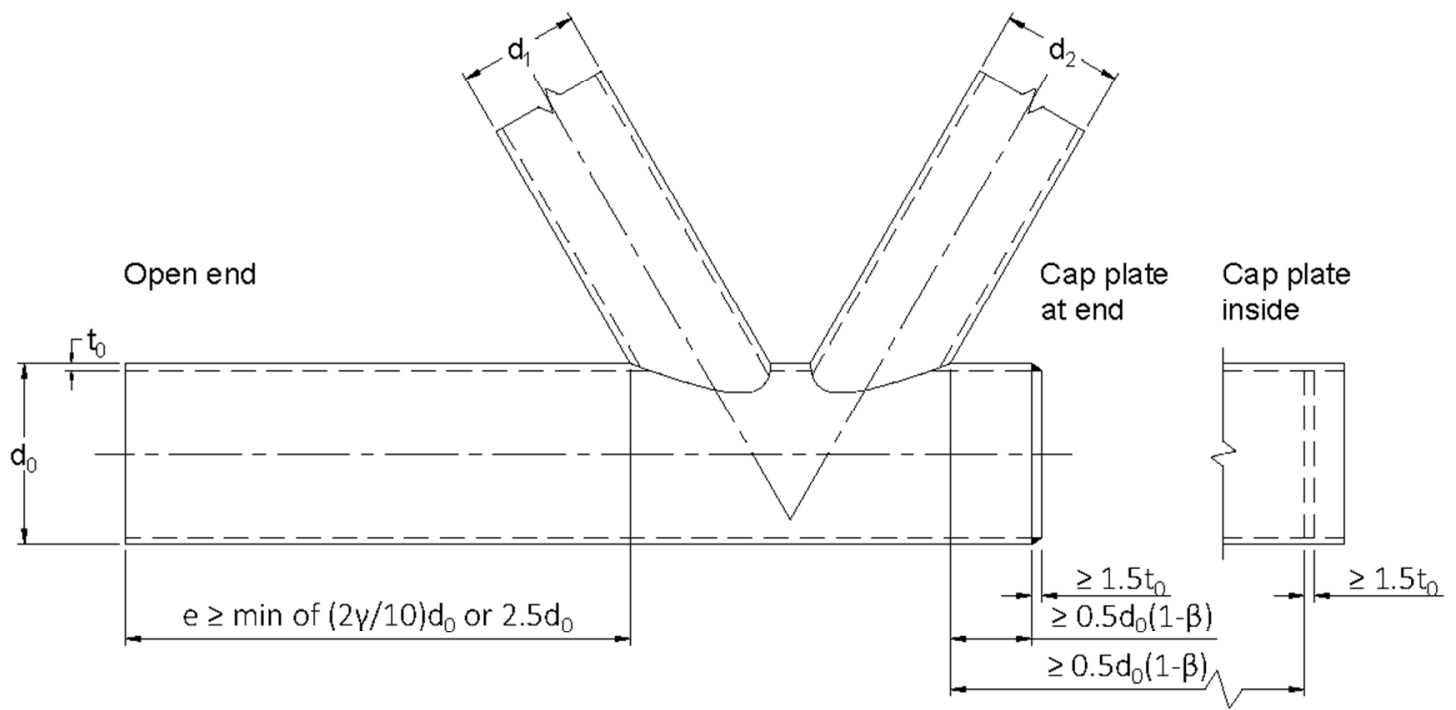

Fig. 2. Proposed end distances in EN 1993-1-8 (shown for CHS)

The $(2 \gamma / 10) d_{0}$ rule which is derived empirically for CHS chords, with a minimum value of $2.5 d_{0}$ included for good engineering practice, is transcribed for rectangular hollow section (RHS) chords by simply replacing the outside dimensions. Specifically, substituting the CHS diameter $\left(d_{0}\right)$ by the largest of the RHS width and depth $\left(b_{0}\right.$ and $\left.h_{0}\right)$ and accounting for the applicable $2 \gamma$ values lead to a large required end distance of $2.5 b_{0}$ or $2.5 h_{0}$ (the minimum stipulated, as shown in Fig. 2) up to $4 b_{0}$ or $4 h_{0}$ (for the maximum $2 \gamma$ of 40 , as permitted by ISO (2013) 
61 for RHS). However, this end-effects rule accommodates the propagation of ovalization of the complete chord member that occurs in CHS connections, whereas with RHS connections chord member distortion is generally more localized and largely confined to the chord connecting face. Also, the research on chord end effects, on which the EN 1993-1-8 formula is based, considered connections that were symmetrical about the branch, while the behaviour of connections with the branch near a chord end may be different. These assumptions indicate that the estimated end distances may be very conservative, thus further research is needed to develop end distance requirements specific to RHS chord members.

If the branch needs to be closer to a chord end, the use of a cap plate is specified. For this case, the respective minimum distance of $0.5 d_{0}(1-\beta)$ and $0.5 b_{0}(1-\beta)$ for CHS and RHS sections is equal to the distance between the branch and the chord side walls, to ensure a similar stiffness around the branch. While this end distance may be necessary for fabrication details, it should not be an issue for strength. The minimum cap plate thickness of $1.5 t_{0}$ is based on engineering judgement so that it has sufficient stiffness relative to the chord sidewalls (i.e. the ratio of the cap plate to chord sidewall stiffness is $\left(1.5 t_{0}\right)^{3} / t_{0}{ }^{3}=3.38$ ) to restrain local chord deformation and develop the required connection strength.

\section{Analytical Study (Yield Line Analyses)}

Analytical yield line analysis has been used to determine the capacity of flexible HSS connections. When a connection is remote from the RHS chord ends (defined as a "regular" connection), the analytical solution for the yield load $P_{Y}$ (Eq. (1)), associated with the chord face yielding limit state, can be derived based on a symmetric flexural yield line mechanism developing in the chord connecting face (Fig. 3). $Q_{f}$ is a function to account for the effect of chord normal stress, which is less than or equal to one. Eq. (1) has been widely adopted in design recommendations for RHS-to-RHS T-, Y-, and X-connections.

$$
P_{Y} \sin \theta_{1}=\frac{f_{y 0} t_{0}^{2}}{(1-\beta)}\left[\frac{2 h_{1}}{b_{0} \sin \theta_{1}}+4 \sqrt{1-\beta}\right] Q_{f}
$$

In Eq. (2), the full dimensions $h_{1}, b_{1}, b_{0}$ and $\beta$ in Eq. (1) are replaced by the more accurate effective dimensions $h_{1}^{\prime}, b_{1}^{\prime}, b_{0}^{\prime}$ and $\beta^{\prime}$ where:

- $h_{1}$ is increased to account for the fillet weld size, or $h_{1}^{\prime}=h_{1} / \sin \theta_{1}+2 w$ 
86

89

(2)

- $b_{1}$ is increased to account for the fillet weld size, or $b_{1}^{\prime}=b_{1}+2 w$

- $b_{0}$ is decreased to reflect plastic hinges forming in the centre of the chord walls, or $b_{0}{ }^{\prime}=b_{0}-t_{0}$

- branch-to-chord width ratio $\beta=b_{1} / b_{0}$ is increased to $\beta^{\prime}=b_{1}^{\prime} / b_{0}^{\prime}$

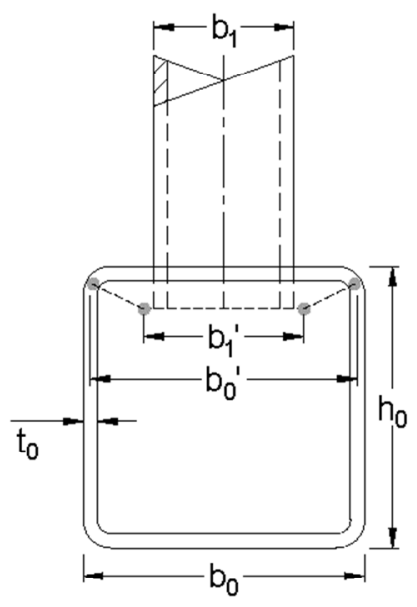

$$
P_{Y}^{\prime} \sin \theta_{1}=\frac{f_{y 0} t_{0}{ }^{2}}{\left(1-\beta^{\prime}\right)}\left[\frac{2 h_{1}^{\prime}}{b_{0}^{\prime}}+4 \sqrt{1-\beta^{\prime}}\right] Q_{f}
$$
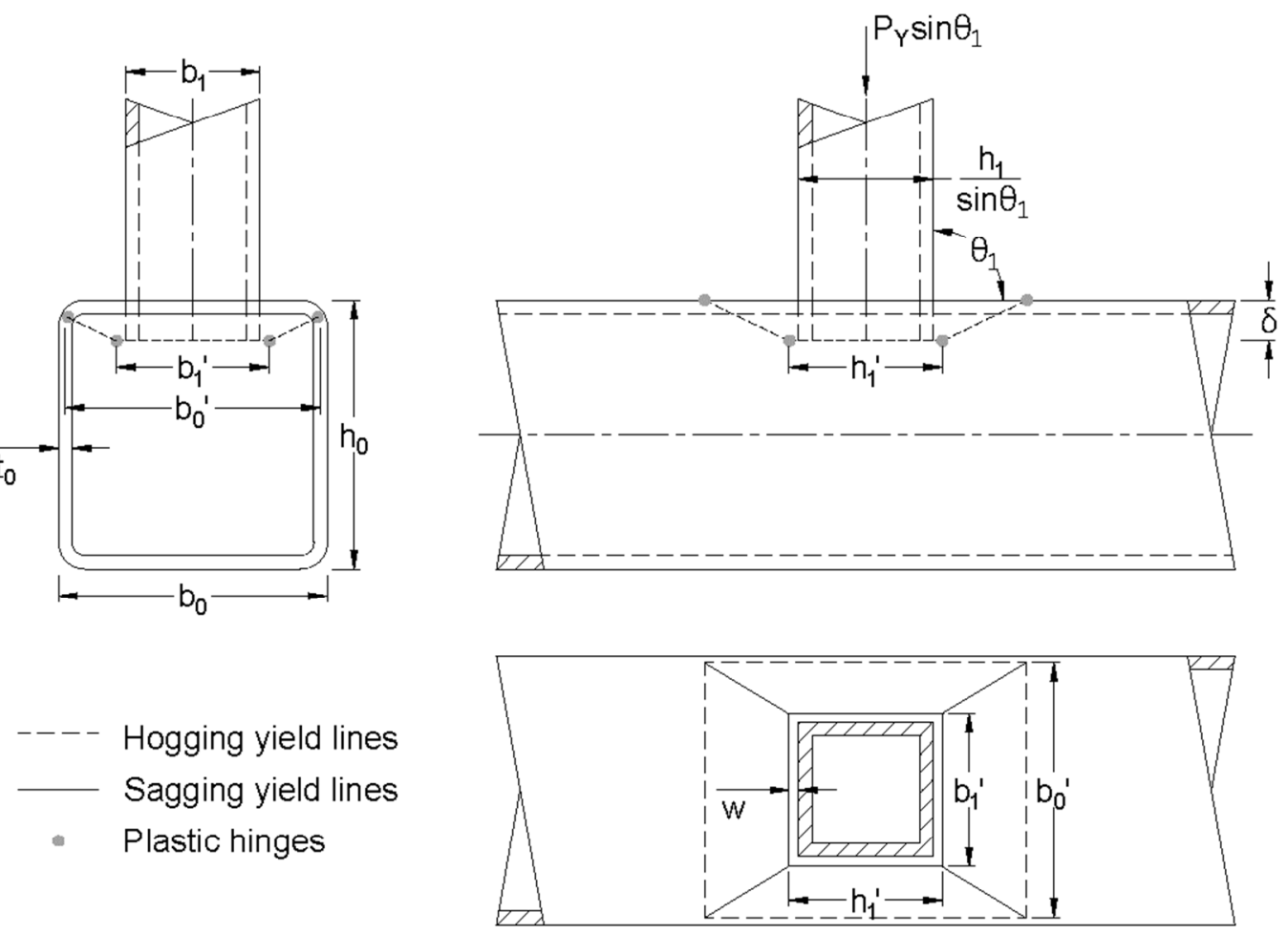

90

Fig. 3. Yield line mechanism for a regular RHS-to-RHS axially-loaded X-connection

If $\beta$ approaches unity, the yield load tends to infinity and this limit state is not likely to be critical. $\beta \leq 0.85$ thus represents a practical upper limit for the application of the yield line solution.

When a connection is close to a RHS chord end (termed an "offset" connection), there may not be adequate lengths to develop the traditional yield line mechanism. Potential asymmetric flexural yield line mechanisms are therefore proposed and investigated for their ability to predict the yield loads of the offset connections, where solutions for $e_{\min }$ can also be derived by comparison with Eqs. (1) or (2).

A first possible flexural yield line mechanism no. 1 (Fig. 4) is studied. The analytical yield load solution, for a known end distance $e$ from the branch edge to an open chord end, is given by Eq. (3). 


$$
P_{Y, 1} \sin \theta_{1}=\frac{f_{y 0} t_{0}^{2}}{(1-\beta)}\left[\frac{2 e}{b_{0}}+\frac{2 h_{1}}{b_{0} \sin \theta_{1}}+2 \sqrt{1-\beta}\right] Q_{f}
$$
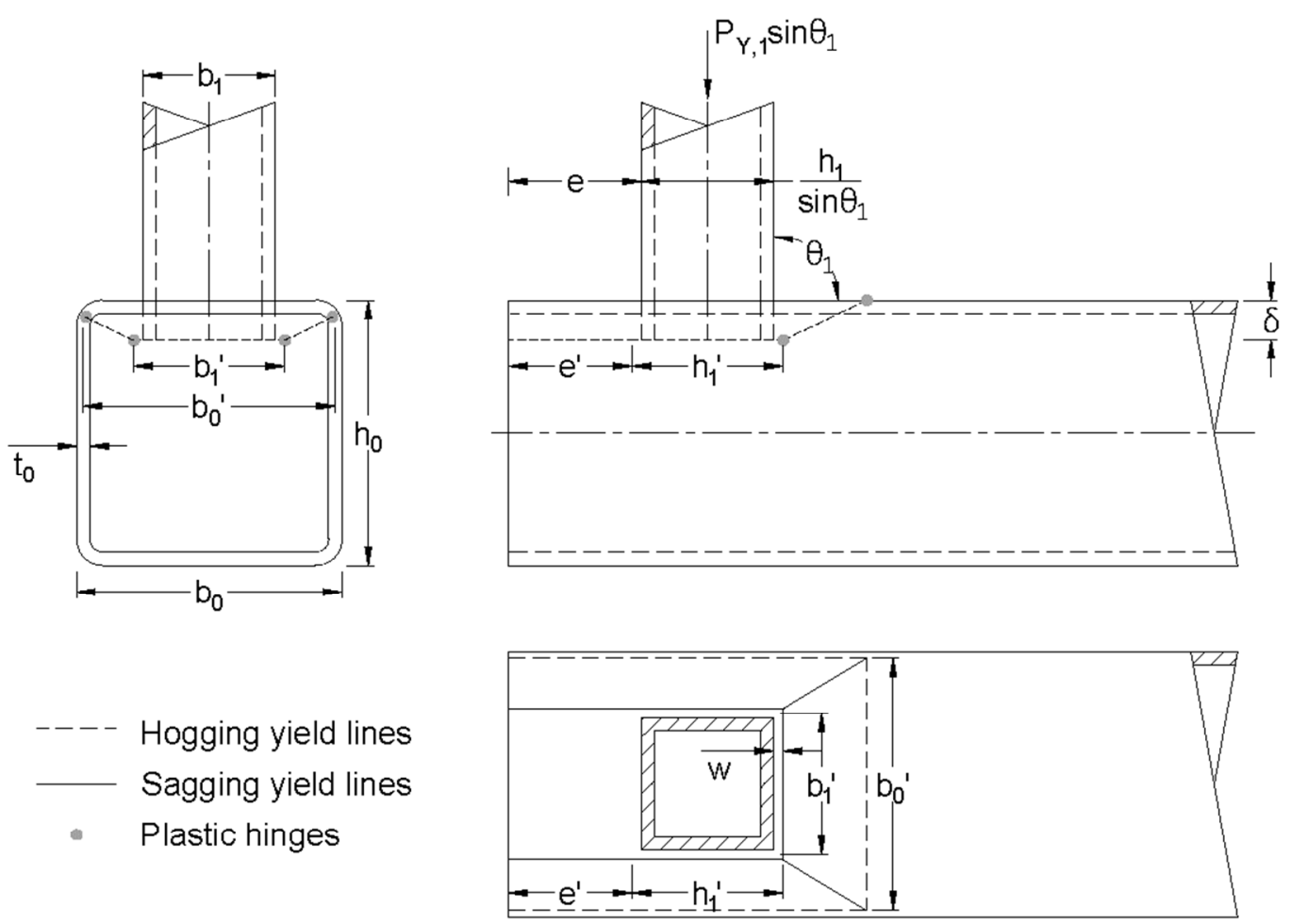

101

$$
P_{Y, 1}^{\prime} \sin \theta_{1}=\frac{f_{y 0} t_{0}^{2}}{\left(1-\beta^{\prime}\right)}\left[\frac{2 e^{\prime}}{b_{0}^{\prime}}+\frac{2 h_{1}^{\prime}}{b_{0}^{\prime}}+2 \sqrt{1-\beta^{\prime}}\right] Q_{f}
$$

111 112 to the traditional yield line mechanism (Eq. (1)) if the end distance is less than:

$$
e_{\min }=b_{0} \sqrt{1-\beta}
$$
represents the minimum connection strength. $b_{0}^{\prime}, \beta^{\prime}$ and $e^{\prime}$, where $e$ is reduced to account for the fillet weld size, or $e^{\prime}=e-w$.

The associated minimum end distance is then:

$$
e_{\min }=b_{0}^{\prime} \sqrt{1-\beta^{\prime}}+w
$$

Fig. 4. Yield line mechanism No. 1 for an offset RHS-to-RHS axially-loaded X-connection

It can be shown that this postulated yield line mechanism controls and predicts a lower yield load compared

If $e \geq e_{\min }$, end distance will not be critical and the yield load for the regular T-, Y-, or X-connection

In Eq. (5), the full dimensions $h_{1}, b_{1}, b_{0}, \beta$ and $e$ in Eq. (3) are substituted with effective dimensions $h_{1}^{\prime}, b_{1}^{\prime}$, 
113 A second possible flexural yield line mechanism no. 2 (Fig. 5) is also investigated in the yield line 114 predictions (Eq. (7), where $m$ is the slope of the inclined yield line from the branch side to the open chord end).

115 This mechanism applies only if $\mathrm{e} \leq m b_{1} / 2$ or $\mathrm{e} \leq m b_{1}^{\prime} / 2+w$ (i.e. if the yield lines have not converged).

116

$$
P_{Y, 2} \sin \theta_{1}=\frac{f_{y 0} t_{0}^{2}}{(1-\beta)}\left[\left(2+\frac{1}{m^{2}}\right) \frac{e}{b_{0}}+\frac{2 h_{1}}{b_{0} \sin \theta_{1}}+2 \sqrt{1-\beta}+\frac{1}{2 m}\right] Q_{f}
$$
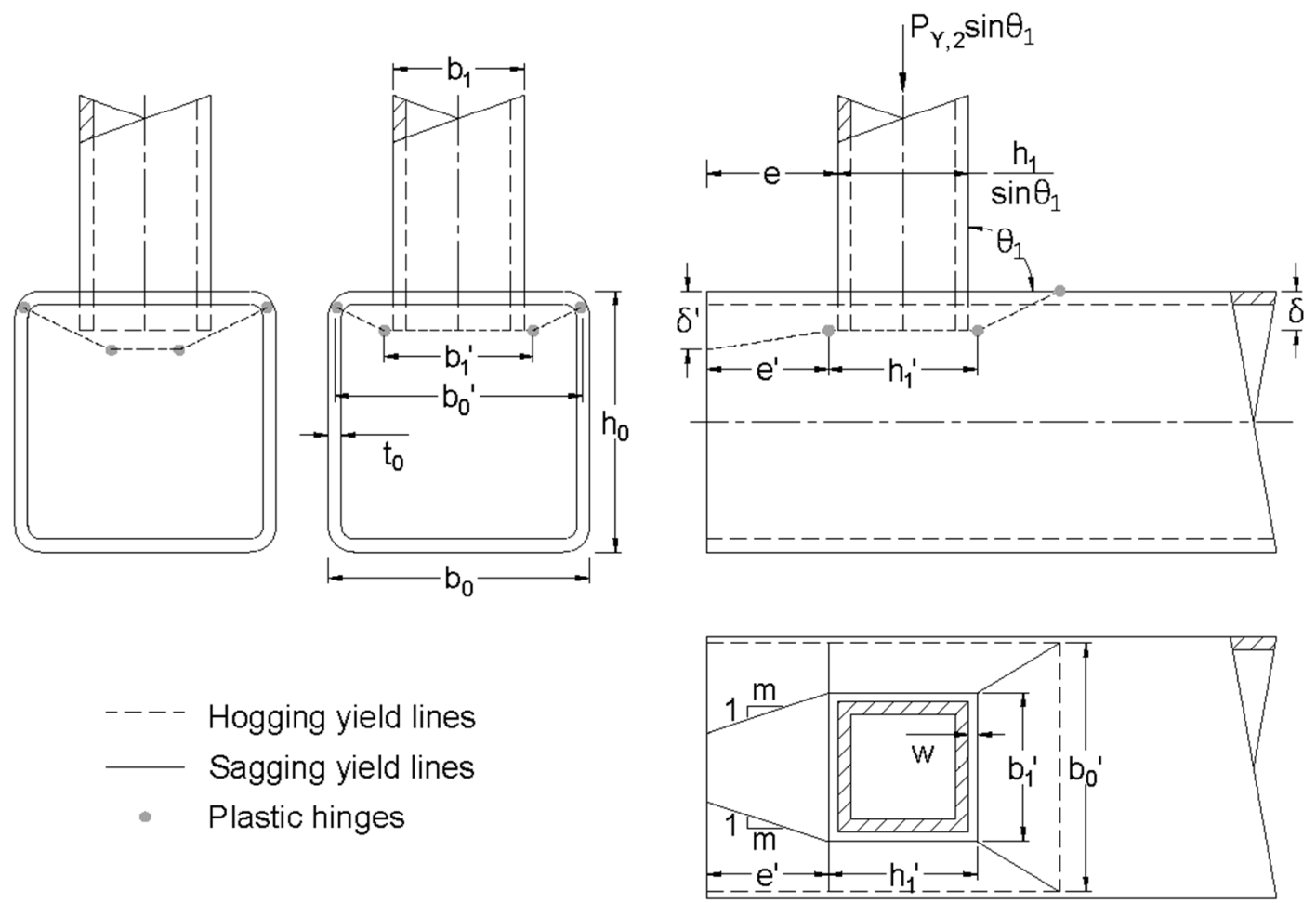

117

118

119

120

121

122

123

124

125

Fig. 5. Yield line mechanism No. 2 for an offset RHS-to-RHS axially-loaded X-connection

This approximate yield line mechanism governs over the regular yield line mechanism (Eq. (1)), if the end distance is less than:

$$
e_{\min }=b_{0}[\sqrt{1-\beta}-1 /(4 m)] /\left[1+1 /\left(2 m^{2}\right)\right]
$$

If $e \geq e_{\min }$, end distance will not be critical.

In Eq. (9), the full dimensions $h_{1}, b_{1}, b_{0}, \beta$ and $e$ in Eq. (7) are substituted with effective dimensions $h_{1}{ }^{\prime}, b_{1}{ }^{\prime}$, $b_{0}^{\prime}, \beta^{\prime}$ and $e^{\prime}:$

The corresponding minimum end distance is then: 


$$
e_{\min }=b_{0}^{\prime}\left[\sqrt{1-\beta^{\prime}}-1 /(4 m)\right] /\left[1+1 /\left(2 m^{2}\right)\right]+w
$$

A third possible flexural yield line mechanism no. 3 (Fig. 6) is considered as well (Eq. (11), where $x$ is the mechanism applies only if $e>x$ or $e>x^{\prime}+w$ (i.e. if the yield lines have converged).

131

$$
P_{Y, 3} \sin \theta_{1}=\frac{f_{y 0} t_{0}^{2}}{(1-\beta)}\left[\frac{2 e}{b_{0}}+\frac{2 h_{1}}{b_{0} \sin \theta_{1}}+2 \sqrt{1-\beta}+\frac{b_{1}(1+\beta)}{4 x}\right] Q_{f}
$$
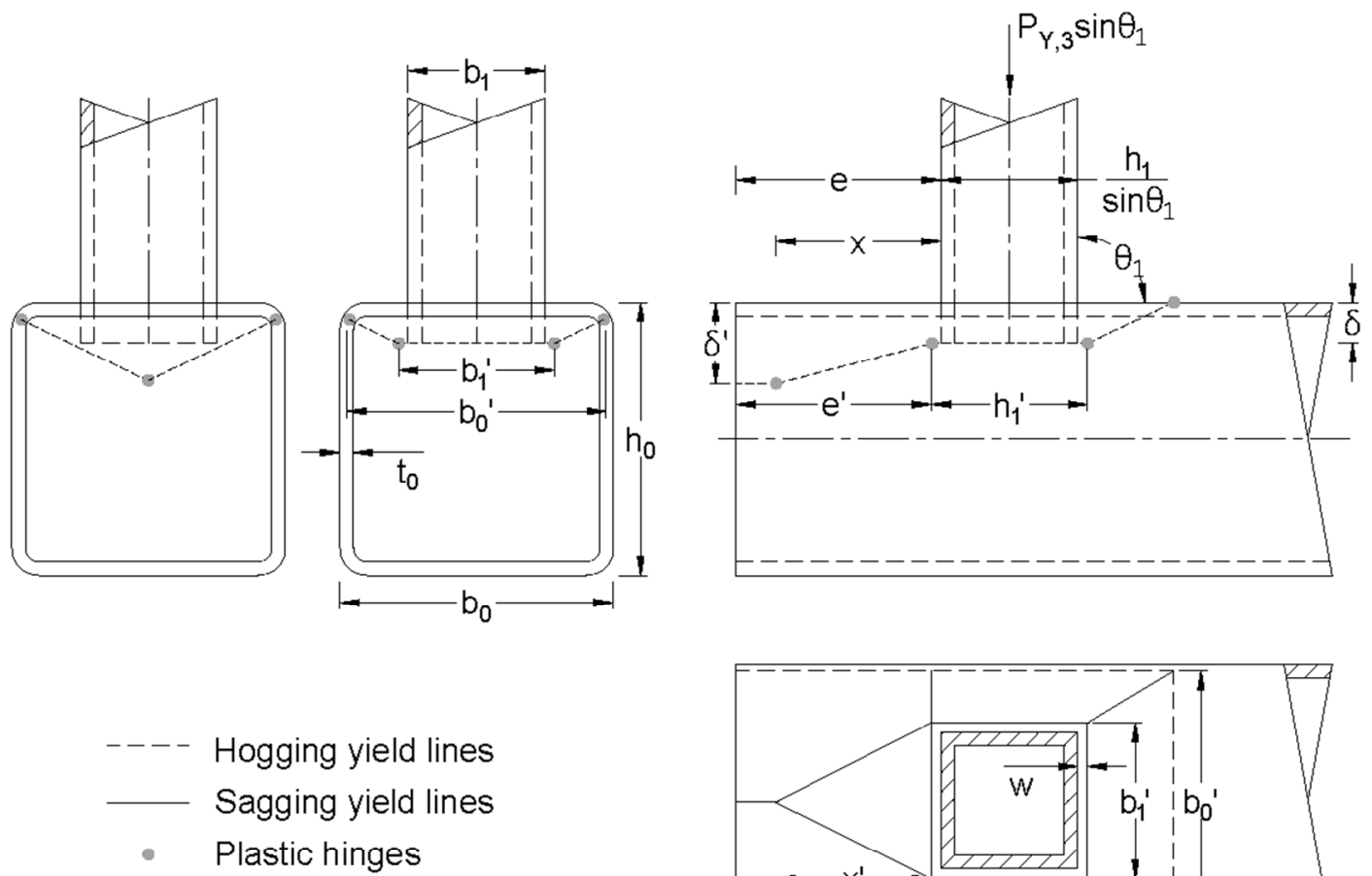

132

133

134

139

Fig. 6. Yield line mechanism No. 3 for an offset RHS-to-RHS axially-loaded X-connection

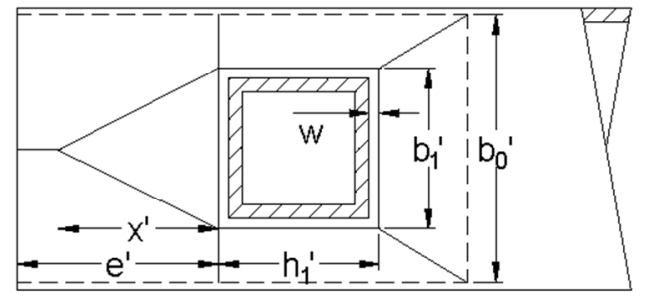

mechanism in the applicable range will generally be greater than the yield load predicted by the regular yield line mechanism. Thus, it is not a critical mechanism for end effects, and a minimum end distance does not apply.

In Eq. (12), the full dimensions $h_{1}, b_{1}, b_{0}, \beta, e$ and $x$ in Eq. (11) are substituted with effective dimensions $h_{1}^{\prime}$, $b_{1}^{\prime}, b_{0}^{\prime}, \beta^{\prime}, e^{\prime}$ and $x^{\prime}$, where $x$ is reduced to account for the fillet weld size, or $x^{\prime}=x-w$. 
The ratios of $e_{\min } / b_{0}$, calculated for mechanisms nos. 1 and 2 using Eqs. (4) and (8), are plotted against $\beta$ (i.e. represented by the two lines) in Fig. 7, which shows that $e_{\min }$ is always less than $b_{0}$ for all values of $\beta$. Thus, according to the yield line solution, a conservative end distance equal to the chord member width can be used for a branch connected close to an open chord end.

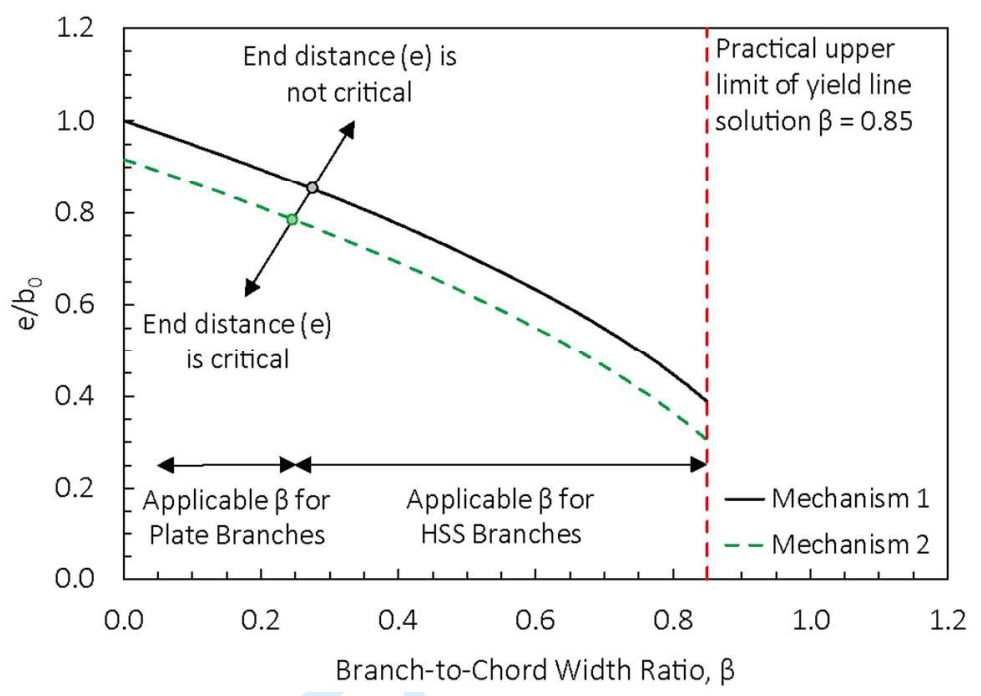

Fig. 7. $e_{\min } / b_{0}$ vs. $\beta$ based on postulated yield line mechanisms

However, as the minimum end distances are derived analytically, they have not been substantiated by experimental evidence. The formulae are also only a function of $\beta$, the branch-to-chord width ratio, and do not account for the possible influence of other connection parameters (e.g. $2 \gamma$, the chord slenderness ratio). Further, a yield line mechanism, which is based on a chord face flexure limit state, may not always govern. For $\beta>0.85$, which is outside the yield line theory applicability, a sidewall failure limit state may control.

\subsection{Ultimate Deformation Limit Applied to Tests}

The connection capacity at the ultimate limit state can be determined from experimental or numerical loaddisplacement results as the lower of, as implemented by IIW (2012) and shown in Fig. 8:

(a) The maximum load resulting from ultimate failure if this load occurs at a lower displacement than (b); or

(b) The load corresponding to an ultimate deformation limit

A connecting face deformation equal to $3 \%$ of the RHS chord width $\left(0.03 b_{0}\right)$ or $3 \%$ of the CHS chord diameter $\left(0.03 d_{0}\right)$ has generally been used as the ultimate deformation limit in (b), as proposed by Lu et al. 
157

158

159

160

161

162

163

164

165

166

167

168

169

170

171

172

173

174

175

176

been investigated (Zhao 2000; Kosteski and Packer 2003a, 2003b; Kosteski et al. 2003). As the 3\% $b_{0}$ ultimate deformation limit load $N_{1,3 \%}$ was shown to agree well with the analytical yield load $P_{Y}$ for these regular connections, it will also be used as a limit to the connection capacity and to validate the proposed yield line formulae for the offset connections.

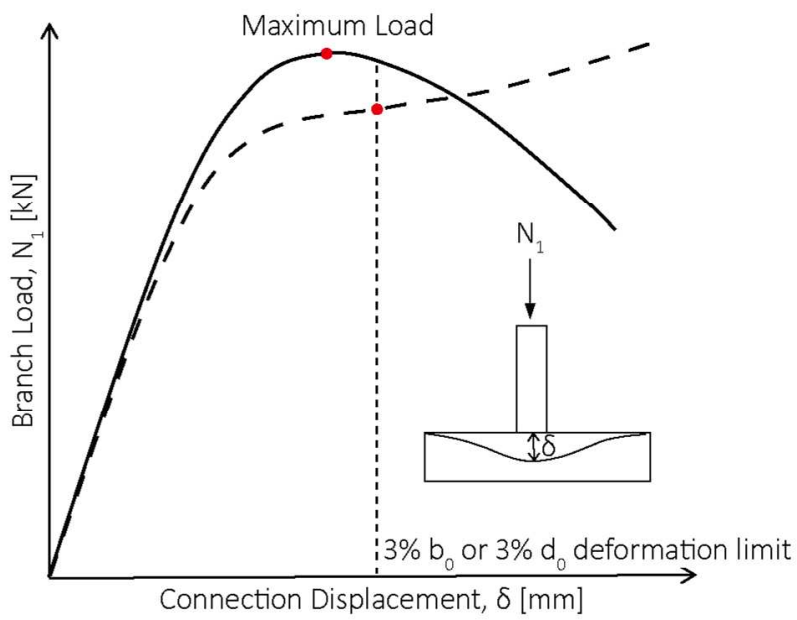

Fig. 8. Failure criteria (adapted from Wardenier et al., 2010)

\section{Experimental Program}

An experimental program was undertaken to investigate the behaviour of connections near an open chord end, evaluate the proposed yield line models, and assess the EN 1993-1-8 amendments for RHS welded connections.

\subsection{Test Specimens and Measured Dimensions}

Twelve isolated, square HSS-to-HSS X-connection tests were performed, with the branch loaded in axial compression and centred laterally on the chord. The connections were designed with "thick branches welded to thin chords" in order to generate connection failure before reaching the branch member capacity. This is against tubular design principles in practice, when the objective would be to avoid a connection failure. All chord and branch members were made of cold-formed HSS sections. The branch members were produced to ASTM A847 (2014), which is a weathering steel grade, but has similar strength properties as ASTM A500 Grade C. The cap plate materials were made to CSA G40.21 (2013) Grade 350W. Two chord sizes (HSS 203x203x6.35 and HSS

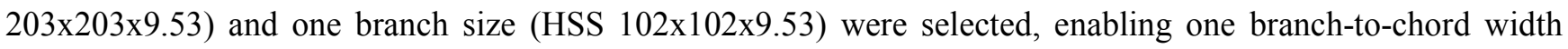
ratio (nominal $\beta=0.5$ ) and two chord slenderness ratios (nominal $2 \gamma=32$ and 21). An empirical parametric 
177

178

180

181

182

183

184

185

186

187

188

189

190

191

192

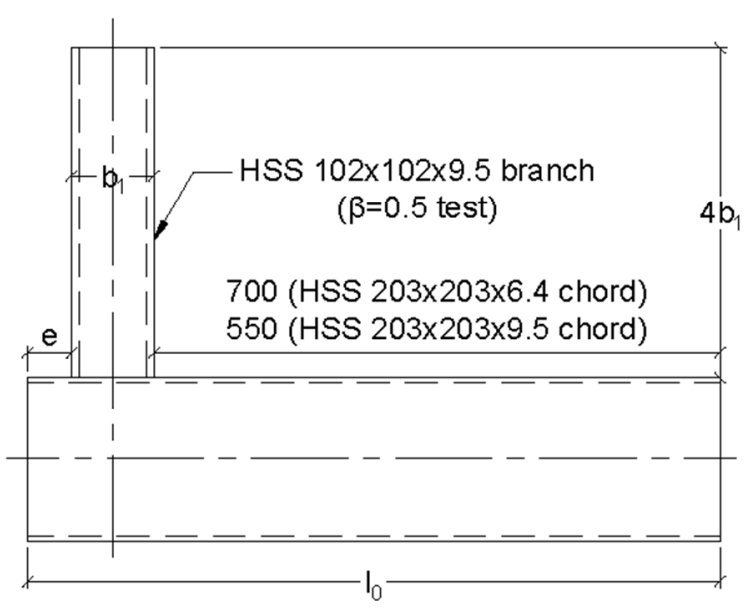

(a) without a cap plate

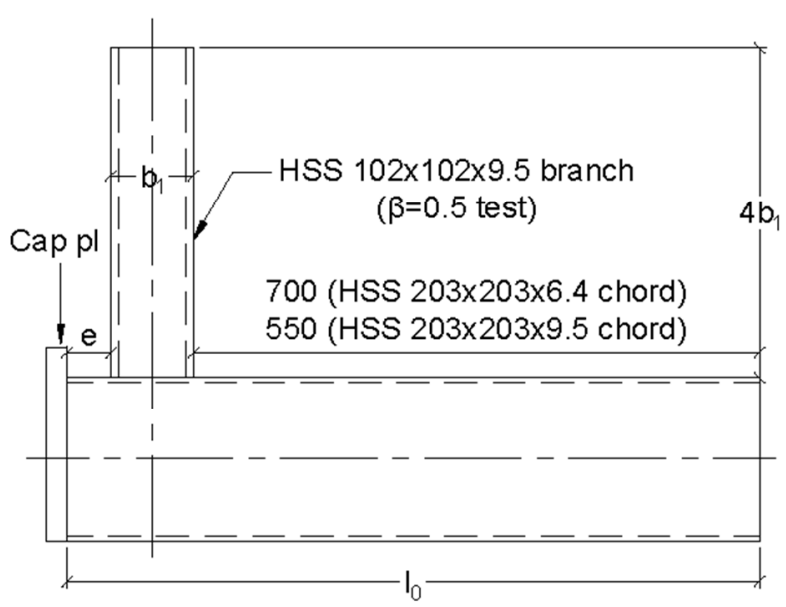

(b) with a cap plate

Fig. 9. Square HSS-to-HSS X-connection test specimens 
Table 1. Test specimens and measured dimensions

\begin{tabular}{lcccc}
\hline \multicolumn{1}{c}{$\begin{array}{c}\text { Specimen } \\
\text { no. }\end{array}$} & $\begin{array}{c}\text { Specimen } \\
\text { identification }\end{array}$ & $2 \gamma$ & $\begin{array}{c}\text { End distance } \\
\mathrm{e}[\mathrm{mm}]\end{array}$ & $\begin{array}{c}\text { Chord length } \\
1_{0}[\mathrm{~mm}]\end{array}$ \\
\hline 1 & $\mathrm{X}-0.5-32-25 \mathrm{O}$ & 34 & 24 & 827 \\
2 & $\mathrm{X}-0.5-32-55 \mathrm{O}$ & 34 & 55 & 764 \\
3 & $\mathrm{X}-0.5-32-100 \mathrm{O}$ & 34 & 100 & 796 \\
4 & $\mathrm{X}-0.5-32-160 \mathrm{O}$ & 34 & 160 & 875 \\
5 (control) & $\mathrm{X}-0.5-32-700 \mathrm{O}$ & 34 & 714 & 1530 \\
6 (+cap plate) & $\mathrm{X}-0.5-32-55 \mathrm{C}$ & 34 & 55 & 759 \\
7 & $\mathrm{X}-0.5-21-25 \mathrm{O}$ & 23 & 25 & 687 \\
8 & $\mathrm{X}-0.5-21-55 \mathrm{O}$ & 23 & 54 & 718 \\
9 & $\mathrm{X}-0.5-21-100 \mathrm{O}$ & 23 & 101 & 771 \\
10 & $\mathrm{X}-0.5-21-160 \mathrm{O}$ & 23 & 160 & 828 \\
11 (control) & $\mathrm{X}-0.5-21-550 \mathrm{O}$ & 23 & 560 & 1222 \\
12 (+cap plate) & $\mathrm{X}-0.5-21-55 \mathrm{C}$ & 23 & 55 & 731 \\
\hline
\end{tabular}

Note: measured $\beta=0.50$ for all specimens.

\subsection{Test Setup and Instrumentation}

The experiments were performed using a $5000 \mathrm{kN}$-capacity Baldwin testing frame. The connection was supported on a pedestal, which was secured to the laboratory floor. A steel collar was fitted around the branch at the top to prevent any lateral movement and the steel collar was welded to a steel plate, which was then bolted to the machine head. The branch could then be centred vertically with the load application and support points. The $\mathrm{X}$-connection was thus tested under direct transverse compression rather than as a simply supported Tconnection, which removed any chord normal stress effects on the connection results and hence $Q_{f}=1.0$ (discussed further by Packer et al., 2017). This configuration also enabled the end distance to be varied for the different test specimens.

All connections were instrumented with a linear variable differential transformer (LVDT) placed between the top of the pedestal and the bottom of the machine head to monitor the total branch elastic deformation and connection local deformation. A system, which consisted of a K610 optical camera that recorded the global coordinates of light-emitting-diode (LED) targets positioned on the test specimens, was used to measure the vertical connection displacements and chord face deformation profiles. For four connections, when the branch 
212 for both HSS chord sizes, strain gauges were installed around the branch perimeter to measure the non-uniform 213 strain distribution close to the connection and the bending moment distribution along the branch height. Typical 214 test setups are shown in Fig. 10.

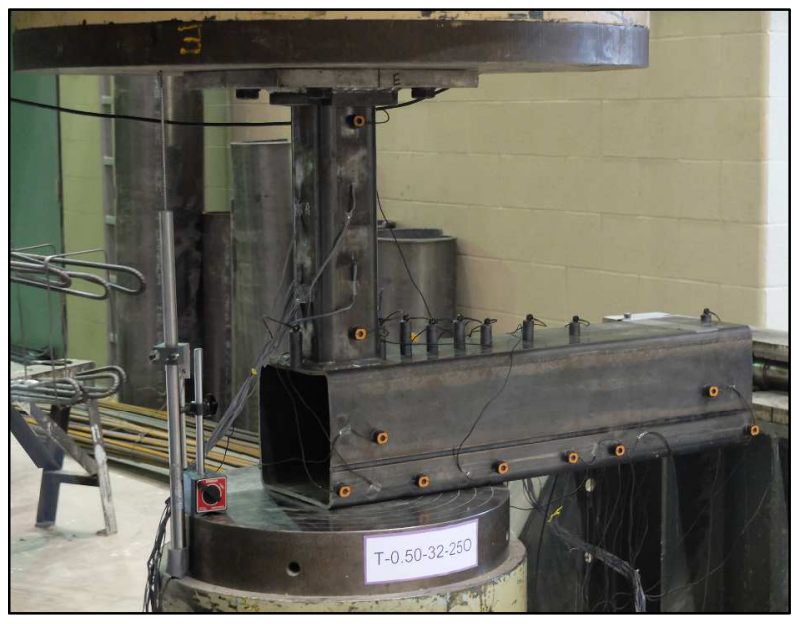

(a) Specimen with e $=25 \mathrm{~mm}$

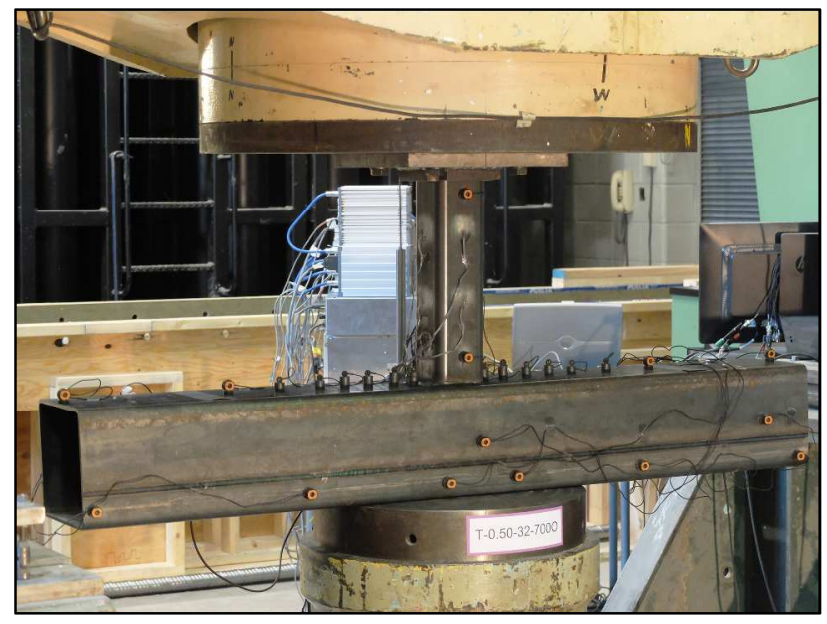

(b) Control specimen

Fig. 10. Typical test setups

216

\section{Experimental Results}

\subsection{Geometric and Material Properties}

Cross sections of the RHS branch and chord members were cut with a thickness of 1 in., machined, and traced in AutoCAD to obtain the outside dimensions, inside/outside corner radii, as well as the cross-sectional areas of the flat faces, corners, and full sections of the RHS members. The wall thicknesses were measured with a 1-in. Mitutoyo micrometer. The average geometric properties are given in Tables 2 and 3. Since the measured thickness of the chord members exceeds the 5\% tolerance on the wall thickness for CSA G40 grade, it was likely made to ASTM A500 grade.

Table 2. Average measured RHS cross-sectional dimensions

\begin{tabular}{|c|c|c|c|c|}
\hline \multirow{2}{*}{$\begin{array}{l}\text { Designation } \\
{[\mathrm{mm}]}\end{array}$} & \multirow{2}{*}{$\begin{array}{l}\text { Width and height } \\
\mathrm{h} \text { and } \mathrm{b}[\mathrm{mm}]\end{array}$} & \multirow{2}{*}{$\begin{array}{c}\text { Wall thickness } \\
\text { t }[\mathrm{mm}]\end{array}$} & \multicolumn{2}{|c|}{ Corner radius } \\
\hline & & & Out., $\mathrm{r}_{\mathrm{o}}[\mathrm{mm}]$ & In., $r_{i}[\mathrm{~mm}]$ \\
\hline HSS $203 \times 203 \times 6.35$ Chord & 203.6 & 5.96 & 14.98 & 8.99 \\
\hline HSS $203 \times 203 \times 9.53$ Chord & 203.1 & 8.85 & 23.82 & 14.98 \\
\hline HSS $102 \times 102 \times 9.53$ Branch & 101.7 & 8.74 & 18.62 & 9.68 \\
\hline
\end{tabular}


Table 3. Measured RHS cross-sectional areas

\begin{tabular}{|c|c|c|c|c|}
\hline \multirow{2}{*}{ Designation $[\mathrm{mm}]$} & \multirow{2}{*}{$2 \gamma$} & \multicolumn{3}{|c|}{ Cross-sectional area, $\mathrm{A}\left[\mathrm{mm}^{2}\right]$} \\
\hline & & Flat & Corner & Total \\
\hline HSS $203 \times 203 \times 6.35$ Chord & 34 & 4046 & 446 & 4492 \\
\hline HSS $203 \times 203 \times 9.53$ Chord & 23 & 5405 & 1090 & 6495 \\
\hline HSS $102 \times 102 \times 9.53$ Branch & 12 & 2225 & 755 & 2980 \\
\hline
\end{tabular}

Standard longitudinal tensile coupons, taken from the three flat sides at least $90^{\circ}$ from the weld seam and from three corners of each of the two RHS chord members used for the connection tests, were cut, machined, and tested in accordance with ASTM E8 (2013). The average material properties, including the yield strength $\left(f_{y}\right)$, ultimate strength $\left(f_{u}\right)$, and rupture strain $\left(\varepsilon_{\text {rup }}\right)$ are summarized in Table 4.

The strengths of the corners are increased relative to the flats (the yield strengths are increased significantly and the ultimate strengths are increased moderately), while the ductility in the corners is reduced (the rupture strains are reduced) due to the greater amount of cold-working. Typical stress-stain plots for the flats and corners of the HSS $203 \times 203 \times 9.53$ chord member are shown in Fig. 11 (a) and (b), respectively.

Table 4. Average measured RHS chord material properties

\begin{tabular}{|c|c|c|c|}
\hline Designation [mm] & $\mathrm{f}_{\mathrm{y}}[\mathrm{MPa}]^{*}$ & $\mathrm{f}_{\mathrm{u}}[\mathrm{MPa}]$ & $\varepsilon_{\text {rup }}$ \\
\hline HSS $203 \times 203 \times 6.35$ flat & 388.8 & 508.7 & 0.287 \\
\hline HSS $203 \times 203 \times 6.35$ corner & 540.5 & 598.9 & 0.176 \\
\hline HSS $203 \times 203 \times 9.53$ flat & 398.1 & 519.8 & 0.306 \\
\hline HSS $203 \times 203 \times 9.53$ corner & 513.8 & 604.4 & 0.219 \\
\hline
\end{tabular}

* Yield strength determined by the $0.2 \%$ offset method.

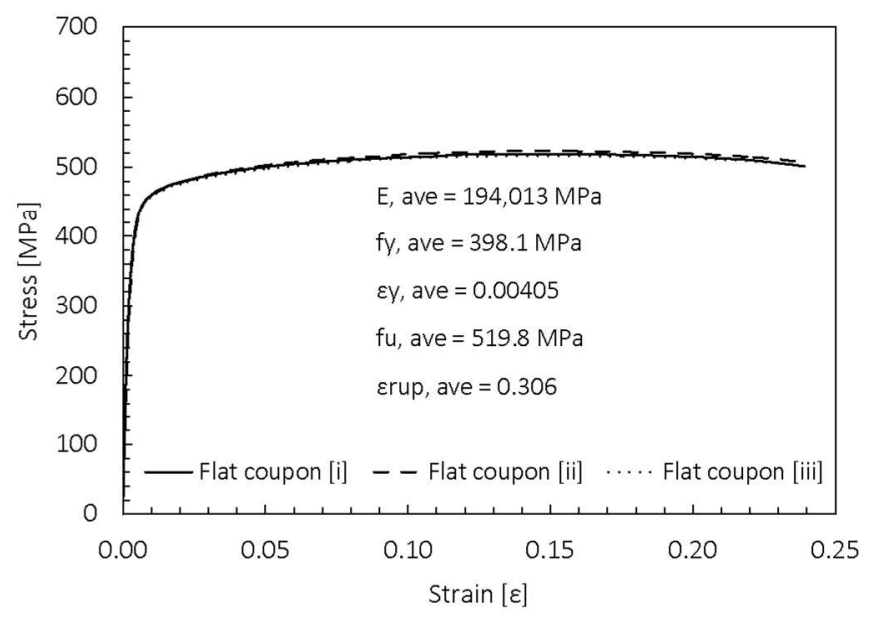

(a) HSS $203 \times 203 \times 9.53$ flat coupons

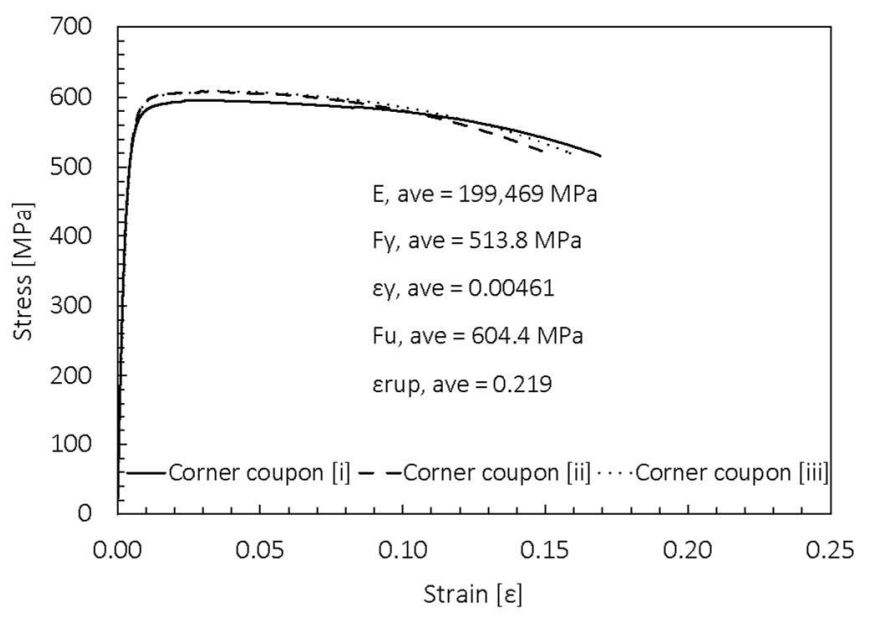

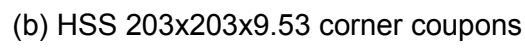

Fig. 11. Typical stress-strain curves from tensile coupon tests 


\subsection{Connection Test Results}

Testing was quasi-static and displacement-controlled to connection failure. Failure of all 12 connections was governed by the chord plastification limit state, which was exhibited by flexural deformation of the chord connecting face. For the connection with a cap plate, the chord face eventually failed in punching shear at the junction with the cap plate. Typical failure modes are illustrated in Fig. 12.

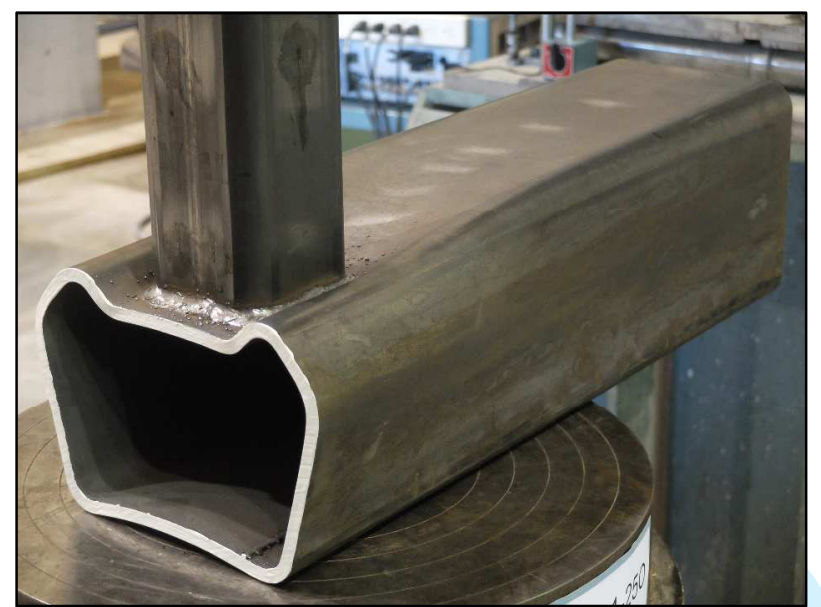

(a) $\mathrm{e}=25 \mathrm{~mm}$

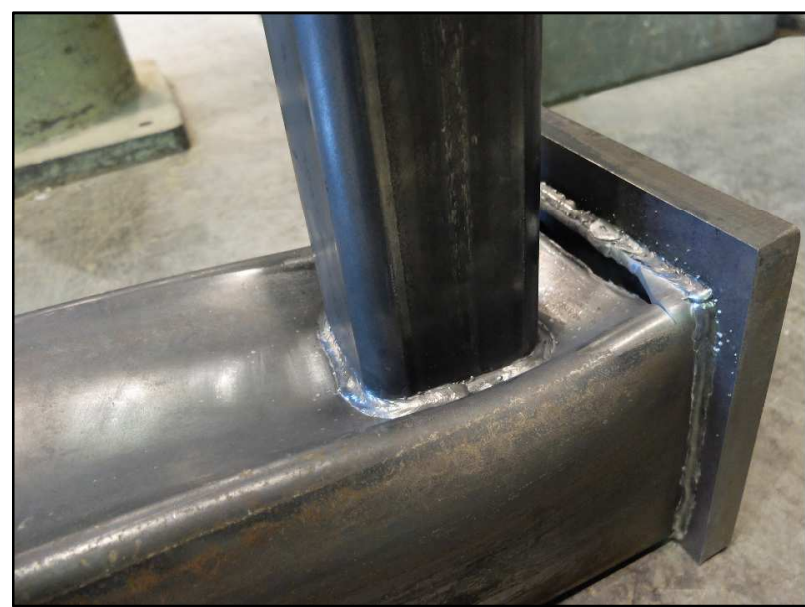

(b) e $=55 \mathrm{~mm}(+$ cap plate)

Fig. 12. Typical failure modes

To obtain the connection load-deformation curve, the branch load was measured by the testing machine's load cell and vertical connection deformation was determined from the global vertical displacement of the LED located close to the connection (on the branch, $50 \mathrm{~mm}$ above the chord face), which also represented the local deformation because the bottom of the HSS chord was restrained from vertical displacement. Typical loaddisplacement behaviours are illustrated in Fig. 13

(a) and (b) for the respectively.

The ultimate connection capacities of all 12 tests were controlled by the $3 \% b_{0}$ deformation limit. The connections exhibited considerable deformation and ductility beyond this point, and strength continued to increase with strain hardening of the HSS material and membrane action in the chord. After punching shear occurred for the connection with a cap plate, the load dropped but the cap plate continued to provide restraint to the chord sidewalls.

Based on the plots, it was found that when the connection is very close $(24-25 \mathrm{~mm})$ to an open chord end, there is a reduction in strength of approximately $27-29 \%$ compared to the regular connection without chord end 
effects. Alternatively, if the chord end is welded with a cap plate, there is an increase in strength of about 27-

$30 \%$ compared to the regular connection.

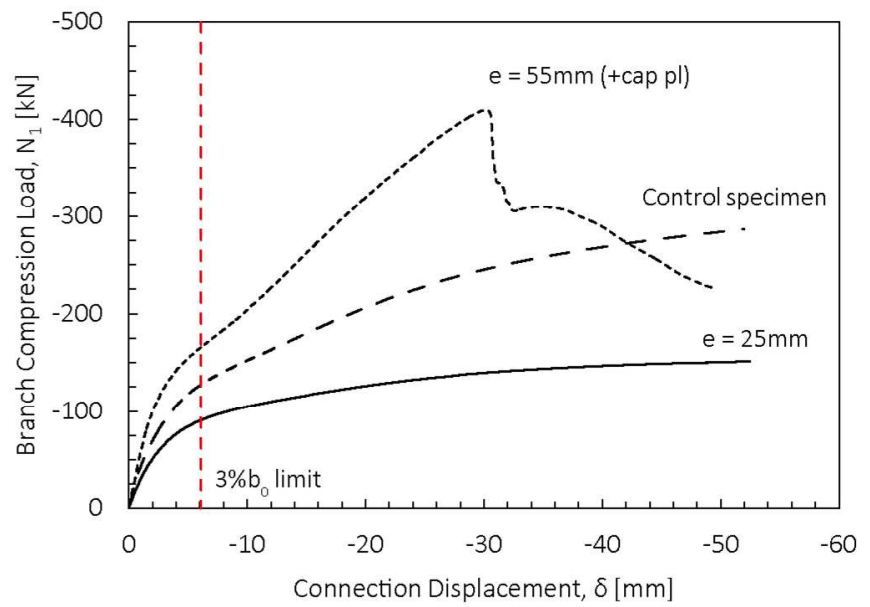

(a) HSS chord with $2 y=34$

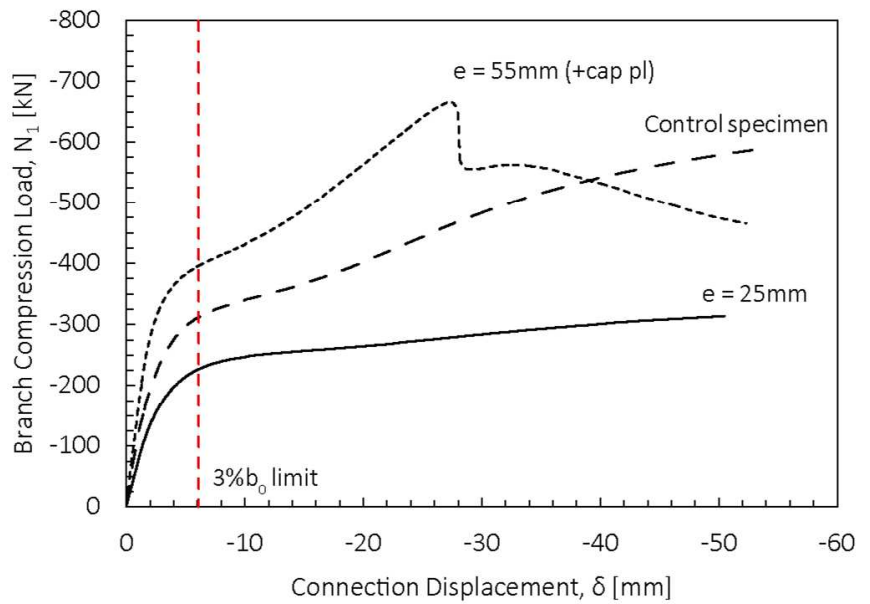

(a) HSS chord with $2 \gamma=23$

Fig. 13. Typical load-displacement curves

The local vertical deformation along the centerline of the top chord face was processed from the LED

chord. The theoretical transverse yield lines at a distance of $0.5 b_{0} \sqrt{1-\beta}$, modified slightly to account for the

weld size $w$, from the edges of the branch are also plotted.

It is shown that deformations were concentrated near the connection and extended for a length of approximately $400 \mathrm{~mm}\left(\approx 2 b_{0}\right)$ and $300 \mathrm{~mm}\left(\approx 1.5 b_{0}\right)$, from the branch edge for the $2 \gamma=34$ and 23 HSS chords, respectively, beyond which there is almost no deformation. This indicates that the chord lengths used, based on the EN 1993-1-8 formula, are conservative in excluding any chord end effects on the connection results.

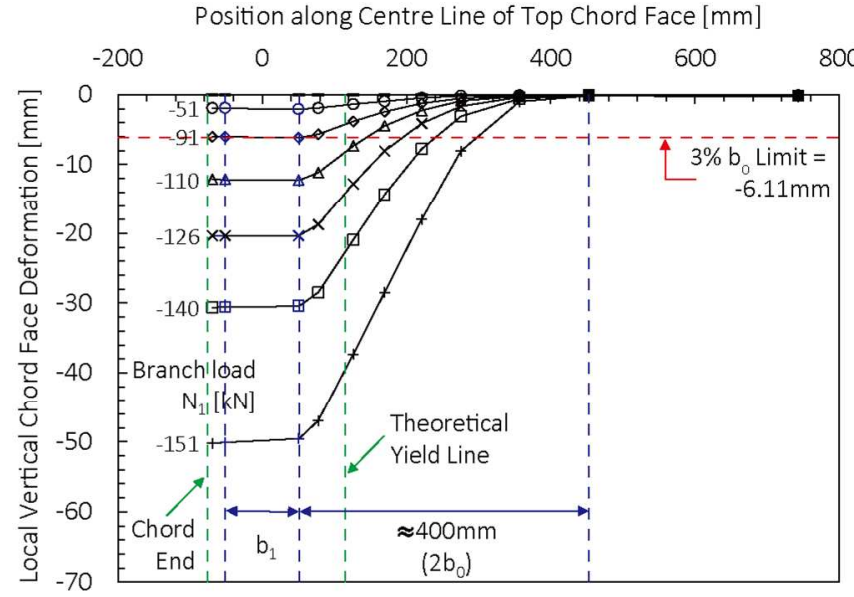

(a) Specimen with $\mathrm{e}=25 \mathrm{~mm}$

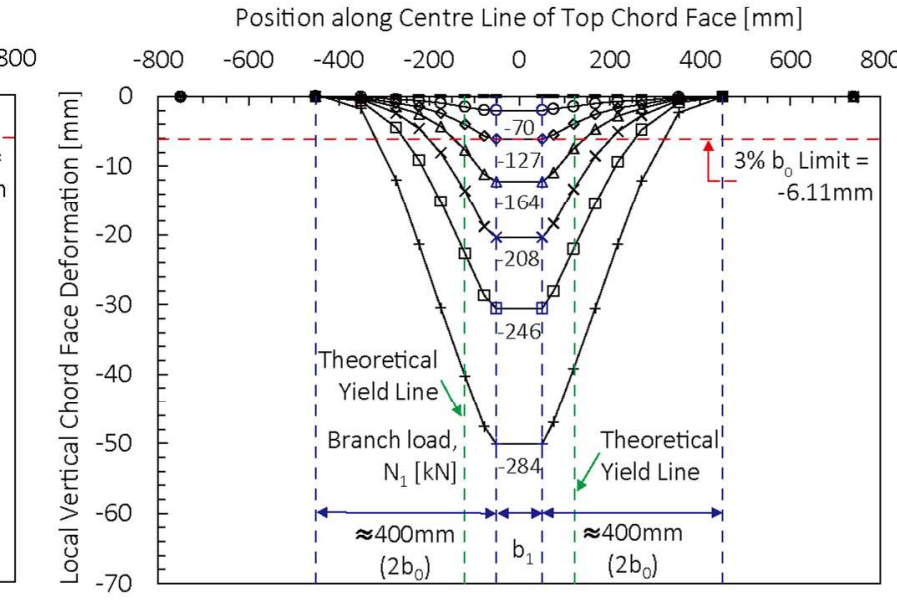

(b) Control specimen

Fig. 14. Typical chord face deformation profiles for HSS chord with $2 y=34$ 
The normal stress distributions around the branch perimeter were processed from the strain gauge readings. Typical plots of these distributions just above the chord face, at the connection load of $N_{1,3 \%}$, are presented in Fig. 15 for the HSS chord with $2 \gamma=34$. The branch remained elastic under all applied loads, with the stresses being well below the nominal yield stress of 345MPa.

It is observed that the branch stress distribution is highly non-uniform near the connection. Maximum compressive stress is seen in the two branch walls parallel to the chord, while minimum compressive stress (or even tensile stress in this case) is seen in the two branch walls transverse to the chord. This shows that the axial load is resisted primarily by the two branch walls parallel to the chord, due to the stiffness of the HSS chord walls. The two branch walls transverse to the chord are much less effective in resisting the load, because of the flexibility of the HSS chord face.

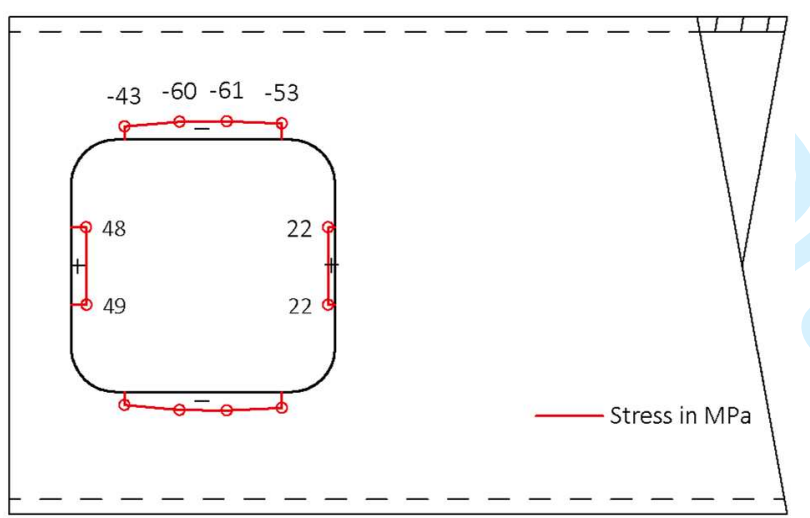

(a) Specimen with e $=25 \mathrm{~mm}\left(\mathrm{~N}_{1,3 \%}=-91 \mathrm{kN}\right)$

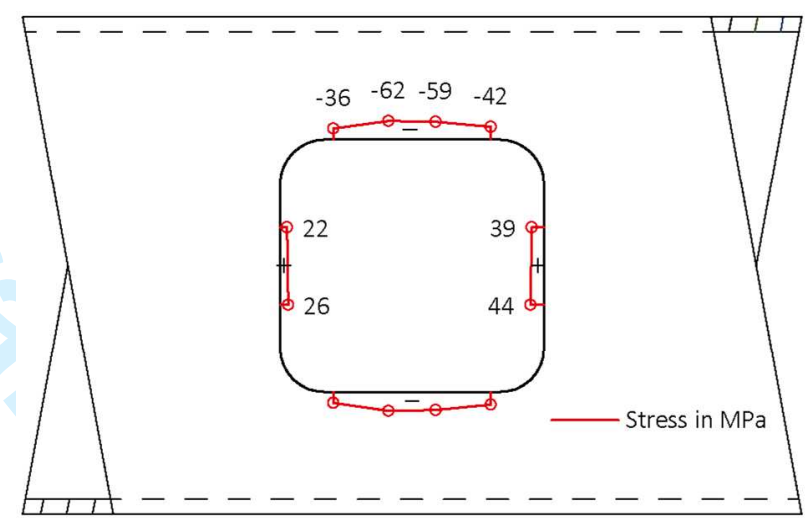

(b) Control specimen $\left(\mathrm{N}_{1,3 \%}=-127 \mathrm{kN}\right)$

Fig. 15. Typical branch stress distribution close to the connection at $\mathrm{N}_{1,3 \%}$ for HSS chord with $2 \gamma=34$

The tensile stresses seen in the branch transverse walls are likely due to interference afforded by the branch against chord face deformation. Specifically, as the chord face, which is supported at the chord walls, attempts to deform in the transverse direction, it is restrained by the branch. Therefore, the branch pulls up, through the weld, on the chord face; and the chord face, through the weld, pulls down on the branch, resulting in the observed tensile stresses in the middle of the transverse branch walls, as illustrated in Fig. 16.

The differences in the stresses between the transverse walls suggest the presence of branch in-plane bending, which may have been caused by branch initial out-of-straightness (for both the offset and regular connections) as well as rotation applied at the branch base and lateral force induced at the branch top, thus leading to higher tensile stresses in the transverse wall closest to the open chord end (for the offset connections). Nevertheless, 
comparable compressive stress distribution along the branch longitudinal walls is seen for both the offset connections $(e=25 \mathrm{~mm})$ and the regular connections (control).

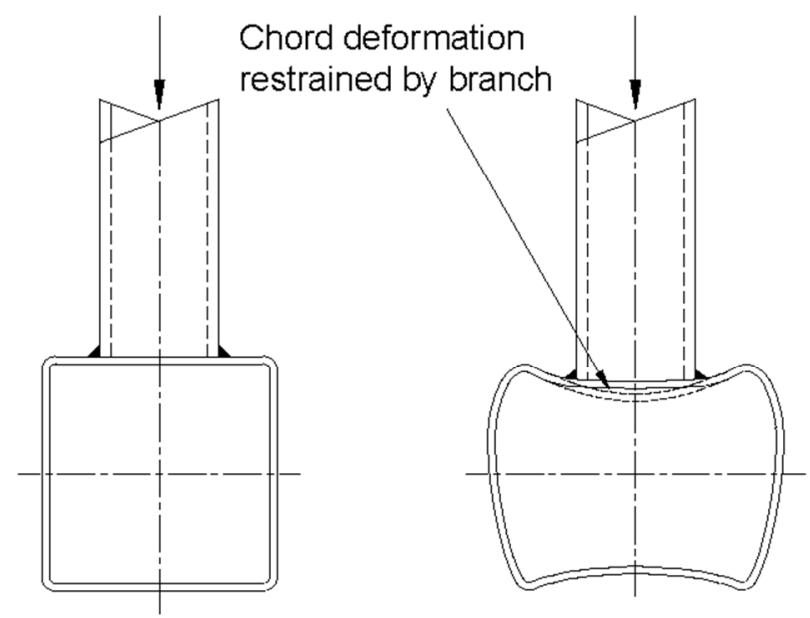

Undeformed geometry

\section{Deformed geometry}

Fig. 16. Geometric compatibility for RHS-to-RHS connection

\section{Evaluation of Results}

\subsection{Comparison with Yield Line Predictions}

In order to evaluate the proposed analytical models, the experimentally-determined yield loads $N_{1,3 \%}$ (the loads at the $3 \% b_{0}$ ultimate deformation limit) are plotted against the end distance $e$ and compared with the different yield line predicted strengths, calculated using measured chord yield strengths $\left(f_{y 0}\right)$, based on the chord flat faces, and with effective dimensions for the chord width $\left(b_{0}{ }^{\prime}\right)$, branch width $\left(b_{1}{ }^{\prime}\right)$, width ratio $\left(\beta^{\prime}\right)$, and end distance $\left(e^{\prime}\right)$. The average weld sizes were used in the calculations. The comparisons for the two sets of six tests using the HSS $203 \times 203 \times 6.35$ and HSS $203 \times 203 \times 9.53$ chords, with an actual chord slenderness $(2 \gamma)$ of 34 and 23 , are presented in Fig. 17 (a) and (b), respectively.

The calculation using effective dimensions is more accurate and increases the yield load value. Since the yield line method is an upper bound method, mechanism no. 1, which computes the lowest yield load, is the critical mechanism. Mechanisms no. 2 and 3, plotted respectively in Fig. 17 for $m=3$ and $x_{1}^{\prime}=b_{1}^{\prime}$ to match experimental observations (Fig. 18 (c) and (d)), never govern. $m=3$ is also used to plot $e_{\min } / b_{0}$ vs. $\beta$ in Fig. 7 using Eq. (8), but it is again not critical. The plots show that the experimental loads agree well with the resulting predicted loads and demonstrate a similar trend. Specifically, for end distances less than approximately $e_{\min }(\mathrm{Eq}$. 
312 (4), the yield line solution based on mechanism no. 1), the strengths of connections near an open chord end are

313 reduced relative to their "regular connection" counterparts. For end distances greater than about $e_{\min }$, the 314 strengths of such connections reach those of their regular counterparts (control specimens). While the test results 315 are very close to the predicted $P_{Y 1}{ }^{\prime}$ values for the $2 \gamma=34$ chord (Fig. 17 (a)), they are slightly higher (but within $31610 \%$ ) for the $2 \gamma=23$ chord (Fig. $17(\mathrm{~b})$ ), which indicates that mechanism no. 1 is still conservative. Thus, 317 overall, the comparison justifies yield line model no. 1 as an accurate predictor of the yield load for the offset connections, with a mean actual/predicted strength of 1.04 and an associated coefficient of variation (COV) of 0.035. Results for connections with a cap plate are not included in the statistical calculation. It is also observed that $e_{\min }$ does not seem to be affected by the chord wall slenderness, based on the trends for the two HSS chords.

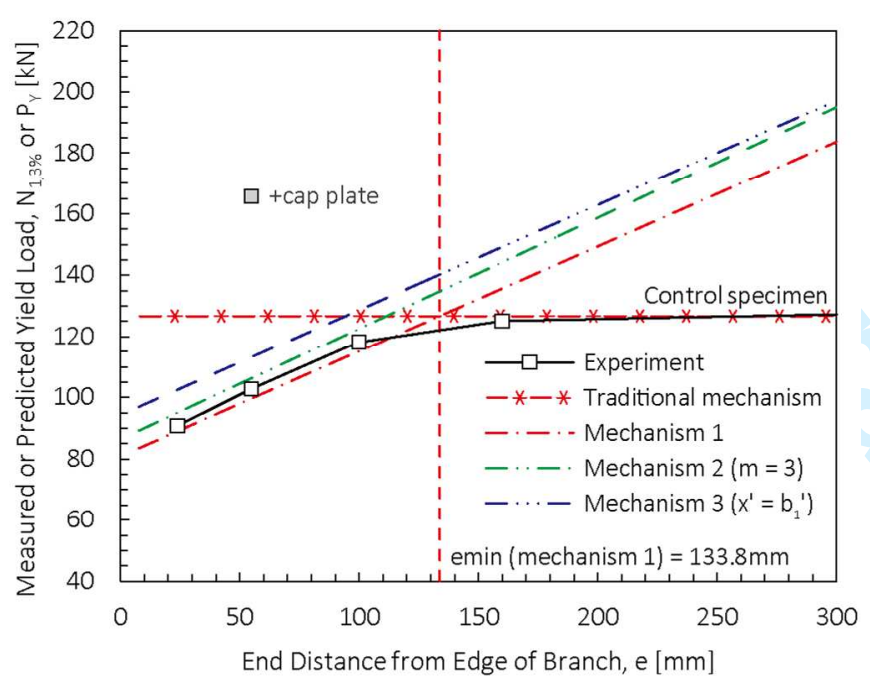

(a) HSS Chord with $2 \mathrm{y}=34\left(\mathrm{f}_{\mathrm{y} 0}=389 \mathrm{MPa}\right)$

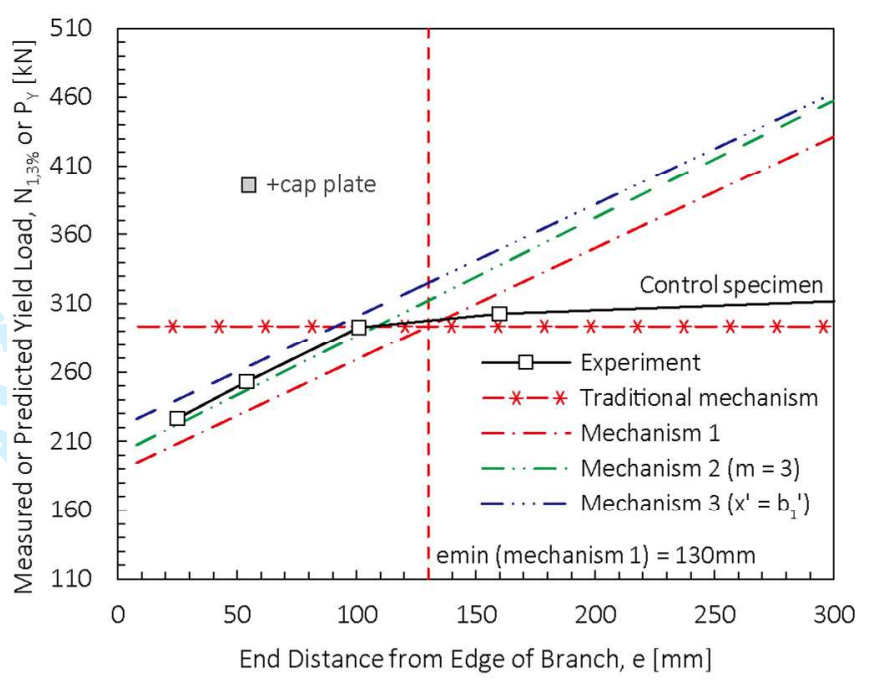

(b) HSS Chord with $2 \mathrm{y}=23\left(\mathrm{f}_{\mathrm{y} 0}=398 \mathrm{MPa}\right)$

Fig. 17. $\mathrm{N}_{1,3 \%}$ or $\mathrm{P}_{Y}$ vs. e (using effective dimensions)

322

323

324

325

326

327

328

330

As designers do not know the weld sizes until the connections have been detailed, design recommendations typically use full dimensions which do not account for the chord wall thickness $t_{0}$ and weld size $w$ in the calculations. The predicted yield line strengths are thus re-calculated using measured chord yield strengths $\left(f_{y 0}\right)$, with full dimensions for the chord width $\left(b_{0}\right)$, branch width $\left(b_{1}\right)$, width ratio $(\beta)$, and end distance $(e)$. The resulting computed values for mechanism no. $1\left(P_{Y 1}\right)$ are found to be always less than the experimental results $\left(N_{l, 3 \%}\right)$ for both the $2 \gamma=34$ and 23 chords, with an overall actual/predicted mean value of 1.29 and a corresponding COV of 0.053 . This shows that yield line model no. 1 , used in conjunction with full (or nominal) dimensions as a simplification, is a conservative predictor of the yield load for the offset connections, and can thus be used for design. This also validates the corresponding yield-line solution for the minimum end distance, 
$331 e_{\min }=b_{0} \sqrt{1-\beta}$, to develop the full connection strength, provided $\beta \leq 0.85$ and chord plastification is the

332 governing failure mode.

333

334

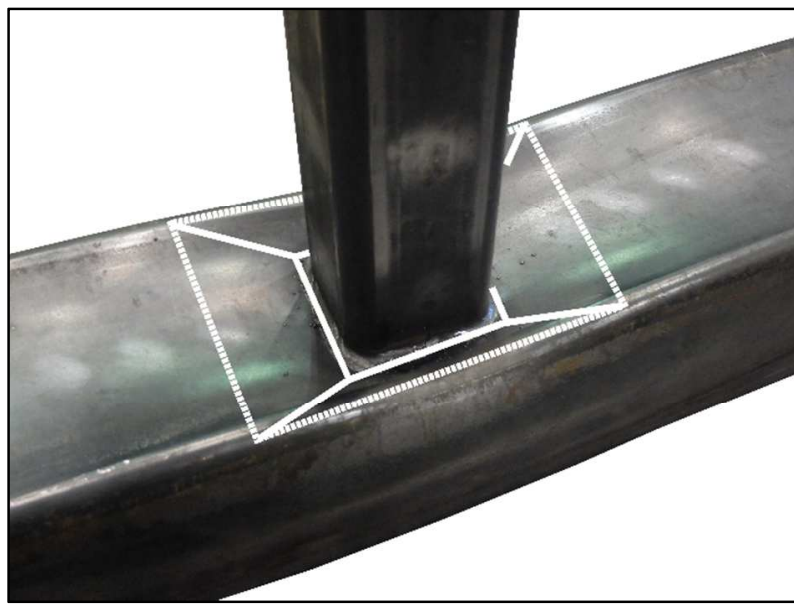

(a) Traditional mechanism (control specimen)

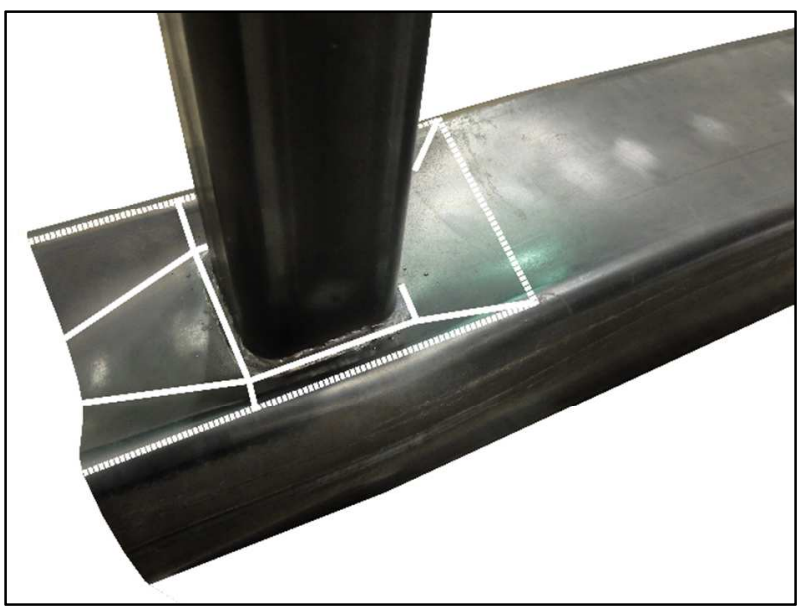

(c) Mechanism $2(e=100 \mathrm{~mm})$

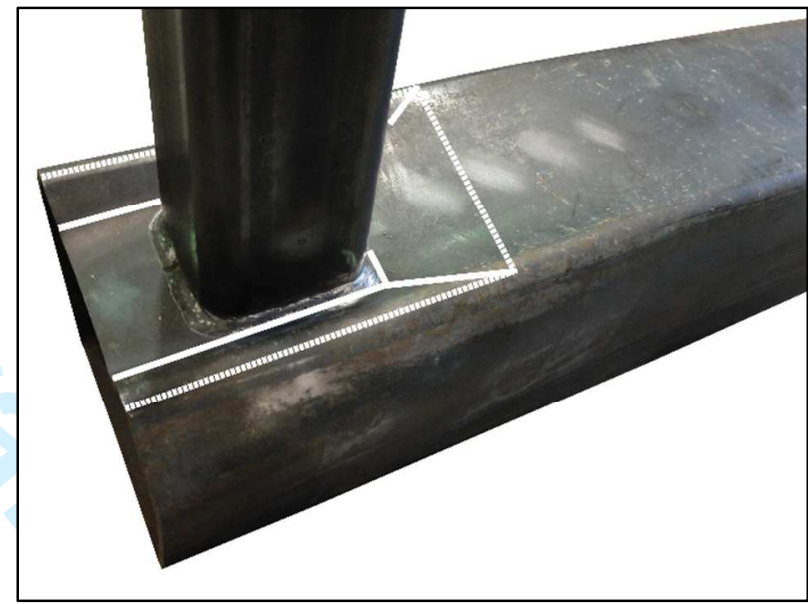

(b) Mechanism $1(\mathrm{e}=55 \mathrm{~mm})$

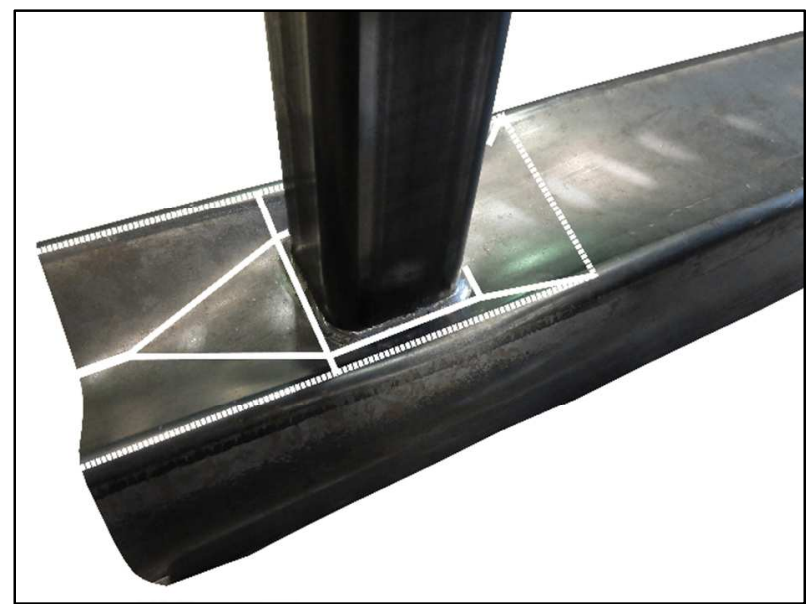

(d) Mechanism $3(e=160 \mathrm{~mm})$

Fig. 18. Observed yield line patterns for HSS chord with $2 y=34$ 


\subsection{Evaluation of EN 1993-1-8 Amendments}

In the proposed amendment to EN 1993-1-8, an end distance greater than the maximum of $(2 \gamma / 10) d_{0}$ or $2.5 d_{0}$, measured from the edge of the branch, is required for CHS connections, in order for the strengths to be predicted by traditional design equations. To assess the applicability of this end distance rule for RHS connections, the diameter $\left(d_{0}\right)$ of the CHS chord is replaced by the width $\left(b_{0}\right)$ of the square HSS chord studied in this research. Substituting $2 \gamma=34$ and 23 for the two HSS chords gives a minimum required end distance of $3.4 b_{0}$ and $2.5 b_{0}$, respectively. This is much larger than that predicted by the yield-line solution of $b_{0} \sqrt{1-\beta}$ or $0.71 b_{0}$, computed with $\beta=0.5$ for both chords, which was found to agree well with experimental results. Thus, the EN 1993-1-8 formula is excessively conservative, and not particularly suitable for estimating the minimum required connection end distances for open-ended chord members used in RHS trusses and girders.

The end connections found in practical applications are typically asymmetrical about the branch. However, the research on end distance effects, on which the EN 1993-1-8 formula is based, examined connections that are symmetrical about the branch. Thus, the recommended EN end distance or chord length is specifically relevant for the design of isolated connections in experimental or numerical tests, in order to develop the traditional yield line mechanism and exclude the influence of chord boundary conditions on the connection strength. In this respect, based on the chord face deformation profiles on both sides of the branch for the regular connections, or on the long-chord side of the branch for the offset connections, a chord length of approximately $2.0 b_{0}$ and $1.5 b_{0}$ was determined to be adequate for the two HSS chords with $2 \gamma=34$ and 23, respectively (see Fig. 14 for the $2 \gamma=34$ chord profiles). These observed values are still less than $3.4 b_{0}$ and $2.5 b_{0}$, calculated above, as the maximum of $(2 \gamma / 10) b_{0}$ or $2.5 b_{0}$. Hence, the EN 1993-1-8 formula is reasonably conservative, and still suitable for determining the minimum required chord lengths of RHS chord members used for isolated "symmetrical" connections in experimental or numerical research.

\subsection{Influence of Providing a Chord End Cap Plate}

As illustrated by the load-displacement curves in Fig. 13 for both HSS chords, adding a cap plate to the 
the $3 \% b_{0}$ deformation limit exceed that of the control specimens, thus indicating that welding a cap plate to the chord end is effective in achieving the full strength of a regular connection.

\subsection{Weld Effective Length for Offset Connections}

Welds may be designed to resist the actual forces in the branch. This requires the use of weld effective lengths, which account for the non-uniform load transfer around the weld perimeter. Suitable effective lengths for RHS T-, Y-, or X-connections subjected to a branch axial load are provided in Table K5.1 of AISC 360-16 (Eq. K5-5) and illustrated in Fig. 19 (a). The effective length is given by:

$$
l_{e}=\frac{2 h_{1}}{\sin \theta_{1}}+2 b_{e}
$$

(Regular RHS connection)

Both Eq. (13) and Fig. 19 (a) show that, for a regular RHS connection associated with a large end distance, it is primarily the two walls or the two welds in the longitudinal direction which are considered effective in resisting the applied loads. This agrees with the branch stress distribution observed for the control specimens at the connection load of $N_{1,3 \%}$ (see Fig. 15 (b) for the $2 \gamma=34$ chord). In Eq. (13), an effective weld length in the transverse direction, taken the same as the effective branch width $b_{e}$ (given by Eq. K1-1 of AISC 360-16) used for checking local yielding of a branch, is also included, where $b_{\mathrm{e}} / 2$ cannot exceed $b_{1} / 4$ when $\beta>0.85$ or $\theta_{1}>50^{\circ}$. Thus, it is acknowledged that a portion of the branch or weld transverse lengths may be considered effective.

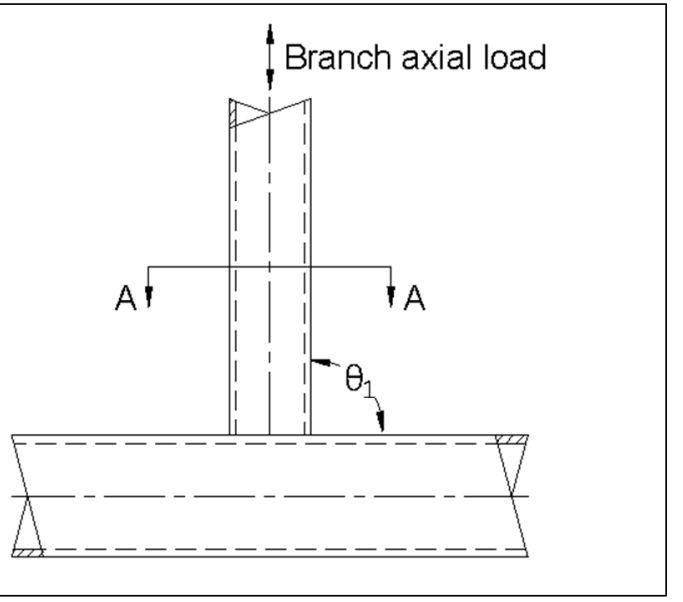

Section A-A

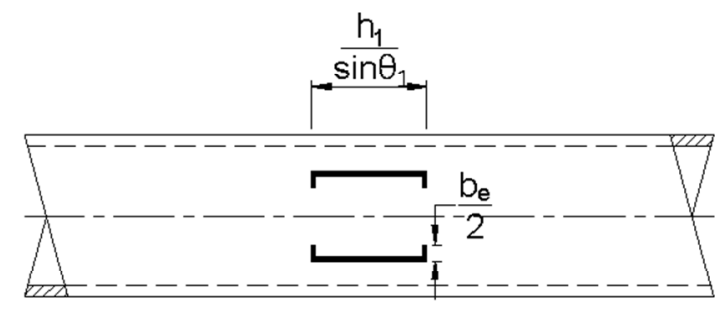

(a) Regular connection 

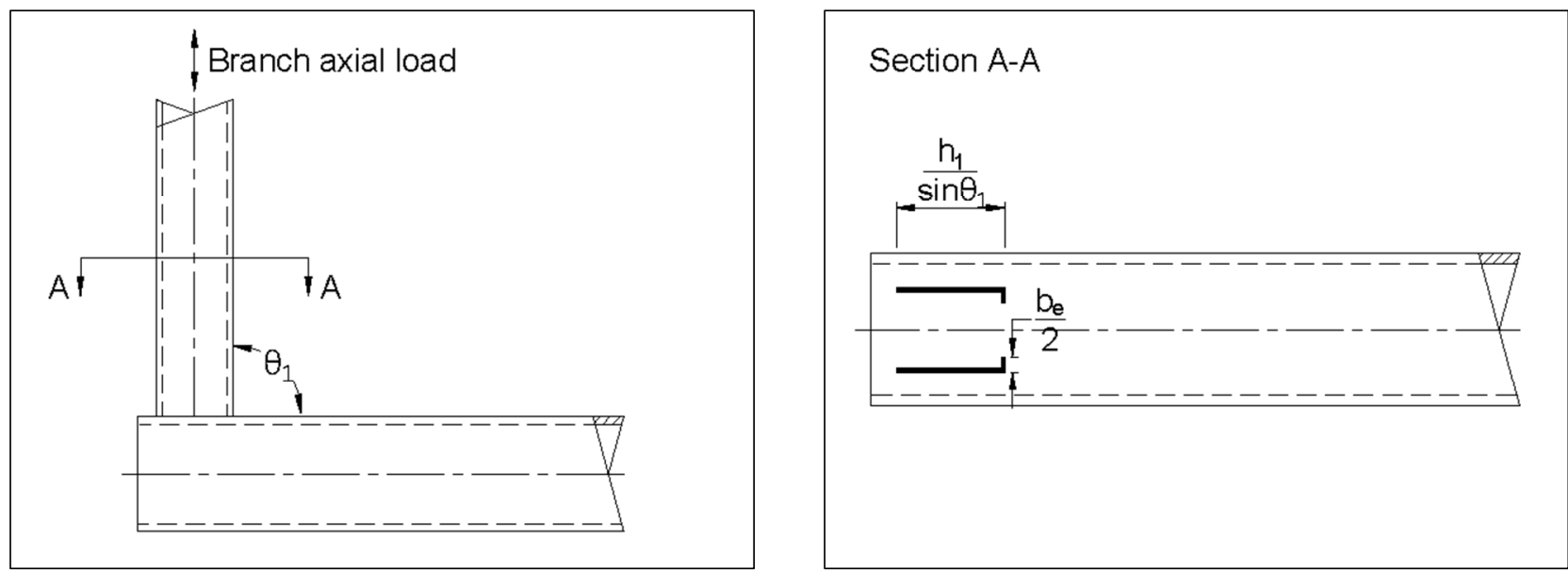

(b) Offset connection

381

382

383

384

385

386

387

388

389

390

391

392

393

394

395

396

397

398

Fig. 19. Effective weld lengths for RHS-to-RHS X-connections $\left(\theta_{1}=90^{\circ}\right)$

As described earlier, the offset connections with $e=25 \mathrm{~mm}$ show a similar compressive stress distribution along the branch longitudinal walls, at the connection yield load, as the control specimens for both HSS chords (compare Fig. 15 (a) with (b) for the $2 \gamma=34$ chord). For the offset connections, the tensile stresses seen in the branch transverse wall closest to the open chord end may render the transverse weld length $b_{\mathrm{e}}$ along this side to be ineffective. Thus, for the case of branch axial loading, the weld effective length developed for a regular RHS connection may be applied, with a slight modification, to an offset RHS connection, as presented by Eq. (14) and Fig. 19 (b).

$$
l_{e}=\frac{2 h_{1}}{\sin \theta_{1}}+b_{e}
$$

(Offset RHS connection)

\section{Conclusions and Recommendations}

Based on the results for the 12 connection tests, shown in Fig. 20, the following conclusions and recommendations are made for RHS-to-RHS axially-loaded T-, Y-, and X-connections:

- When a connection has a small end distance, $e$, to an open chord end, a modified yield line mechanism controls connection failure and produces a connection strength lower than that associated with "regular" connections (remote from the chord ends). The proposed closed-form analytical model herein, which is evaluated against the experimentally-determined $3 \% b_{0}$ deformation limit load, is shown to be an accurate predictor of the yield load $P_{Y}$ for "offset" connections (near an open chord end), and $P_{Y}$ can be conservatively estimated from: 


$$
P_{Y} \sin \theta_{1}=\frac{f_{y 0} t_{0}^{2}}{(1-\beta)}\left[\frac{2 e}{b_{0}}+\frac{2 h_{1}}{b_{0} \sin \theta_{1}}+2 \sqrt{1-\beta}\right] Q_{f} \quad \text { for } e<e_{\min }
$$

where $e_{\min }=b_{0} \sqrt{1-\beta}$ represents the critical end distance at which full connection capacity is achieved.

This minimum end distance, $e_{\min }$, has also been adopted in Table K3.2A of AISC 360-16, as a requirement for the application of traditional design rules for RHS connections. Alternatively, an end distance equal to the chord member width, or $e_{\min }=b_{0}$, is conservative.

- The proposed amendment to EN 1993-1-8, requiring an end distance as the maximum of $(2 \gamma / 10) b_{0}$ or $2.5 b_{0}$ in order to achieve full connection strength, is deemed excessively conservative and not suitable for open-ended RHS chord members in real structures. It is, however, considered suitable (and conservative) for determining the minimum chord lengths of RHS chord members used for isolated, "symmetrical" connections in experimental or numerical tests.

- When a connection is closer to an open chord end than $e_{\min }$, reducing the strength predicted by traditional yield line equations for RHS connections by $50 \%$, in lieu of a detailed calculation, as recommended by the AISC 360-16 Commentary, is safe for design.

- Stiffening the chord end with a cap plate is effective in developing the strength of the connected face against chord plastification. A minimum end distance, $e_{\min }$, does not apply for this case.

- The branch member in an end connection needs to be laterally restrained (which is typically the case when it is connected to the rest of the frame in a real structure) to prevent lateral movement at the branch top, due to a rotation applied at the branch base.

- The weld effective lengths provided for a regular connection, which are used to proportion welds for the actual forces in the branch, can also be applied to an offset connection with a slight modification of $l_{e}=2 h_{1} / \sin \theta_{1}+b_{e}$, for the case of branch axial loading.

The conclusions summarized above, which are all associated with the chord plastification limit state, only apply if $\beta \leq 0.85$. They can be extended to $\mathrm{T}$ - and $\mathrm{Y}$-connections, since flexure of the chord connecting face should produce the same effects in these connections as in the X-connections studied in this research. For a Yconnection with $\theta_{1}<90^{\circ}$, the connection capacity depends on the component of the branch load normal to the chord, $P_{Y} \sin \theta_{1}$, with a branch footprint of $h_{1} / \sin \theta_{1}$, which has been accounted for in the equations above. 


\subsubsection{Application to Other Connection Types}

The minimum end distance developed for the RHS-to-RHS X-connections should be applicable to the following connection types, for the case of branch axial loading:

- Gapped and overlapped K- and N-connections, which consist of a compression branch member pushing into the chord face and a tension branch member pulling out. Compared to X-connections, the resulting chord face deformations are expected to be less.

- Longitudinal plate-to-RHS connections, as the same limit state of chord plastification governs. For these plate-to-RHS connections, $\beta$ would equal $t_{1} / b_{0}$ (typically varying between 0.05 to 0.25 ) and the end distance would be $e_{\min }=b_{0} \sqrt{1-t_{1} / b_{0}}$, where $t_{1}$ is the plate thickness.

- Transverse plate-to-RHS connections, which are generally not governed by chord plastification for practical values of $\beta$ and low compressive stresses in the chord connecting face. However, if either local yielding of the plate or punching shear in the chord is critical, the associated local deformations are expected to be more confined than those produced by chord face plastification.

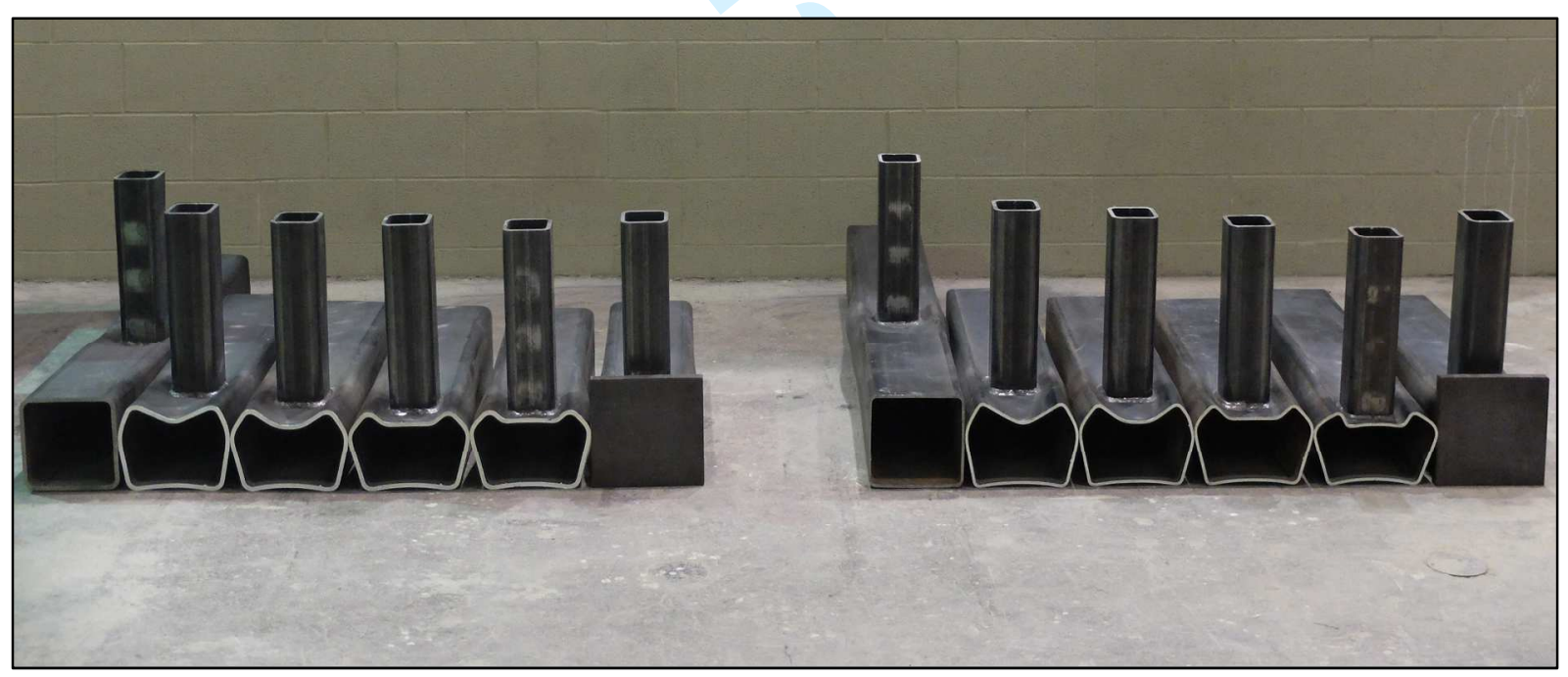

Fig. 20. 12 tested specimens

\section{Acknowledgements}

The authors are grateful for the financial support provided by the Canadian Institute of Steel Construction (CISC) and the Natural Sciences and Engineering Research Council of Canada (NSERC), as well as the in-kind donation of HSS materials by Atlas Tube Inc. and the laboratory assistance of Mr. F. Wei. 
444

\section{References}

AISC. 2010. Specification for structural steel buildings. ANSI/AISC 360-10 Chapter K, American Institute of Steel Construction, Chicago, USA.

AISC. 2016. Specification for structural steel buildings. ANSI/AISC 360-16 Chapter K, American Institute of Steel Construction, Chicago, USA.

ASTM. 2013. Standard test methods for tension testing of metallic materials. ASTM E8/E8M-13a, American Society for Testing and Materials, West Conshohocken, USA.

ASTM. 2014. Standard specification for cold-formed welded and seamless high-strength, low-alloy structural tubing with improved atmospheric corrosion resistance. ASTM A847/A847M-14, American Society for Testing and Materials, West Conshohocken, USA.

CEN. 2005. Eurocode 3: Design of steel structures - Part 1-8: Design of joints. EN 1993-1-8:2005(E), European Committee for Standardization, Brussels, Belgium.

CSA. 2013. General requirements for rolled or welded structural quality steel. CSA G40.20-13/G40.21-13, Canadian Standards Association, Toronto, Canada.

IIW. 2012. Static design procedure for welded hollow section joints - Recommendations, 3rd ed. IIW Doc. XV1402-12, International Institute of Welding, Commission XV, Paris, France.

ISO. 2013. Static design procedure for welded hollow-section joints - Recommendations. ISO 14346:2013(E), International Organization for Standardization, Geneva, Switzerland.

Kosteski, N., and Packer, J.A. 2003a. Welded tee-to-HSS connections. Journal of Structural Engineering, American Society of Civil Engineers, 129(2): 151-159. doi:10.1061/(ASCE)07339445(2003)129:2(151).

Kosteski, N., and Packer, J.A. 2003b. Longitudinal plate and through plate-to-hollow structural section welded connections. Journal of Structural Engineering, American Society of Civil Engineers, 129(4): 478-486. doi:10.1061/(ASCE)0733-9445(2003)129:4(478).

Kosteski, N., Packer, J.A., and Puthli, R.S. 2003. A finite element method based yield load determination procedure for hollow section connections. Journal of Constructional Steel Research, 59(4): 453-471. doi:10.1016/S0143-974X(02)00066-4. 
471 Lu, L.H., de Winkel, G.D., Yu, Y., and Wardenier, J. 1994. Deformation limit for the ultimate strength of hollow 472 section joints. In Proceedings of the 6th International Symposium on Tubular Structures, Melbourne, $473 \quad$ Australia, pp. 341-347.

474 Packer, J.A., and Henderson, J.E. 1997. Hollow structural section connections and trusses - a design guide, 2nd 475 ed. Canadian Institute of Steel Construction, Toronto, Canada.

476

477

478

479

480

481

482

483

484

485

486

487

488

489

490

491

492

493

494

Packer, J.A., Wardenier, J., Zhao, X.L., van der Vegte, G.J., and Kurobane, Y. 2009. Design guide for rectangular hollow section (RHS) joints under predominantly static loading. CIDECT Design Guide No. 3, 2nd ed. CIDECT, Geneva, Switzerland.

Packer, J.A., Puthli, R., van der Vegte, G.J., and Wardenier, J. 2017. Discussion on the paper, "Experimental and numerical assessment of RHS T-joints subjected to brace and chord axial forces”, by Nizer et al. Steel Construction, 10(1): 89-90. doi:10.1002/stco.201770109.

van der Vegte, G.J., and Makino, Y. 2006. Ultimate strength formulation for axially loaded CHS uniplanar Tjoints. Int. Journal of Offshore and Polar Engineering, ISOPE, 16(4): 305-312.

van der Vegte, G.J., and Makino, Y. 2010. Further research on chord length and boundary conditions of CHS Tand X-joints. Advanced Steel Construction, 6(2): 879-890.

Voth, A.P., and Packer, J.A. 2012a. Branch plate-to-circular hollow section connections. II: X-type parametric numerical study and design. Journal of Structural Engineering, American Society of Civil Engineers, 138(8): 1007-1018. doi:10.1061/(ASCE)ST.1943-541X.0000545.

Voth, A.P., and Packer, J.A. 2012b. Numerical study and design of T-type branch plate-to-circular hollow section connections. Engineering Structures, 41: 477-489. doi:10.1016/j.engstruct.2012.03.034.

Wardenier, J., Packer, J.A., Zhao, X.L., and van der Vegte, G.J. 2010. Hollow sections in structural applications, 2nd ed. CIDECT, Geneva, Switzerland.

Zhao, X.L. 2000. Deformation limit and ultimate strength of welded T-joints in cold-formed RHS sections. Journal of Constructional Steel Research, 53(2): 149-165. doi:10.1016/S0143-974X(99)00063-2. 


\section{List of Symbols}

A Cross-sectional area $\left(\mathrm{mm}^{2}\right)$

$b_{e} \quad$ Effective branch width (mm)

$b_{0}, b_{0}^{\prime} \quad$ Nominal/full (out-of-plane) width of RHS chord, effective width $\left(=b_{0}-t_{0}\right)(\mathrm{mm})$

$b_{1}, b_{1}{ }^{\prime} \quad$ Nominal/full (out-of-plane) width of RHS branch, effective width $\left(=b_{1}+2 w\right)(\mathrm{mm})$

$d_{0} \quad$ Outside diameter of CHS chord (mm)

E Modulus of elasticity (MPa)

$e, e^{\prime}, e_{\min } \quad$ End distance from edge of branch to chord end, measured from edge of weld $(=e-w)$, minimum required end distance $(\mathrm{mm})$

$f_{y}, f_{y 0} \quad$ Yield stress of material, yield stress of RHS chord (MPa)

$f_{u} \quad$ Ultimate stress of material $(\mathrm{MPa})$

$h_{0} \quad$ Outside (in-plane) depth of RHS chord (mm)

$h_{1}, h_{1}^{\prime} \quad$ Nominal/full (in-plane) depth of RHS branch, effective depth $\left(=h_{1} / \sin \theta_{1}+2 w\right)(\mathrm{mm})$

$l_{e} \quad$ Effective weld length (mm)

$l_{0} \quad$ Chord length $(\mathrm{mm})$

$m \quad$ Mechanism 2: slope of inclined yield lines from branch side to open chord end

$N_{1} \quad$ Branch axial load (N)

$N_{1,3 \%} \quad$ Connection load at an ultimate deformation of $3 \% b_{0}(\mathrm{~N})$

$P_{Y}, P_{Y}^{\prime} \quad$ Connection load predicted by yield line mechanisms using full, effective dimensions (N)

$Q_{f} \quad$ Chord stress function

$t_{0}, t_{1} \quad$ Wall thickness of HSS chord, wall thickness of HSS/plate branch (mm)

$w \quad$ Measured fillet weld size (horizontal leg length) (mm)

$x, x^{\prime} \quad$ Mechanism 3: distance required for inclined yield lines from edge of branch to open chord end to converge, measured from edge of weld $(=x-w)(\mathrm{mm})$

$\beta, \beta^{\prime} \quad$ Nominal/full width ratio ( $=b_{1} / b_{0}$ for RHS), effective width ratio ( $=b_{1}{ }^{\prime} / b_{0}$, for RHS)

$\delta \quad$ Vertical connection displacement $(\mathrm{mm})$

$\varepsilon_{\text {rup }} \quad$ Rupture strain of material

$2 \gamma \quad$ Chord width (diameter)-to-thickness ratio ( $=2 b_{0} / t_{0}$ for RHS, $=2 d_{0} / t_{0}$ for CHS)

$\theta_{1} \quad$ Included angle between branch and chord $\left({ }^{\circ}\right)$ 


\section{List of Figure Captions}

500 Fig. 1. RHS-to-RHS connection near a truss open end, with chord stiffened

501 Fig. 2. Proposed end distances in EN 1993-1-8 (shown for CHS)

502 Fig. 3. Yield line mechanism for a regular RHS-to-RHS axially-loaded X-Connection

503 Fig. 4. Yield line mechanism No. 1 for an offset RHS-to-RHS axially-loaded X-connection

504 Fig. 5. Yield line mechanism No. 2 for an offset RHS-to-RHS axially-loaded X-connection

505 Fig. 6. Yield line mechanism No. 3 for an offset RHS-to-RHS axially-loaded X-connection

506 Fig. 7. $\mathrm{e}_{\min } / \mathrm{b}_{0}$ vs. $\beta$ based on postulated yield line mechanisms

507 Fig. 8. Failure criteria (adapted from Wardenier et al., 2010)

508 Fig. 9. Square HSS-to-HSS X-connection test specimens

509 Fig. 10. Typical test setups

$510 \quad$ Fig. 11. Typical stress-strain curves from tensile coupon tests

511 Fig. 12. Typical failure modes

512 Fig. 13. Typical load-displacement curves

513 Fig. 14. Typical chord face deformation profiles for HSS chord with $2 \gamma=34$

514 Fig. 15. Typical branch stress distribution close to the connection at $\mathrm{N}_{1,3 \%}$ for HSS chord with $2 \gamma=34$

515 Fig. 16. Geometric compatibility for RHS-to-RHS connection

516 Fig. 17. $\mathrm{N}_{1,3 \%}$ or $\mathrm{P}_{\mathrm{Y}}$ vs. e (using effective dimensions)

517 Fig. 18. Observed yield line patterns for HSS chord with $2 \gamma=34$

518 Fig. 19. Effective weld lengths for RHS-to-RHS X-connections $\left(\theta_{1}=90^{\circ}\right)$

519 Fig. 20. 12 tested specimens 